\title{
Germline IKAROS dimerization haploinsufficiency causes hematologic cytopenias and malignancies
}

Tracking no: BLD-2020-007292R1

Hye Sun Kuehn (Clinical Center, NIH, United States) Julie Niemela (NIH Clinical Center, United States) Jennifer Stoddard (NIH, United States) Sara Ciullini Mannurita (University of Florence, "Anna Meyer" Children's Hospital, Italy) Tala Shahin (St. Anna Children's Cancer Research Institute (CCRI), Austria) Shubham Goel (Clinical Center, NIH, United States) Mary Hintermeyer (Children's Hospital of Wisconsin, United States) Raul Jimenez Heredi (Ludwig Boltzmann Institute for Rare and Undiagnosed Diseases, ) Mary Garofalo (National Institutes of Health, United States) Laura Lucas (Children's Healthcare of Atlanta, Emory University School of Medicine, United States) Smriti Singh (Emory School of Medicine, United States) Annalisa Tondo (University of Florence, Italy) Zachary Jacobs (The Center for Allergy \& Immunology, Kansas City Physician Partners, United States) William Gahl (NHGRI NIH, ) Sylvain Latour (Instutut IMAGINE, Hôpital Necker, France) James Verbsky (Medical College of Wisconsin, United States) John Routes (Medical College of Wisconsin, United States) Charlotte Cunningham-Rundles (Mount Sinai School of Medicine, United States) Kaan Boztug (St. Anna Children's Cancer Research Institute (CCRI), Austria) Eleonora Gambineri (University of Florence; 'Anna Meyer' Children's Hospital, Italy) Thomas Fleisher (NIH, United States) Shanmuganathan Chandrakasan (Aflac Cancer and Blood Disorders Center, Emory/Children's Healthcare of Atlanta, United States) Sergio Rosenzweig (Clinical Center, NIH, United States)

\section{Abstract:}

IKAROS is a transcription factor forming homo/hetero-dimers and regulating lymphocyte development and function. Germline mutations affecting IKAROS N-terminal DNA binding domain, acting in a haploinsufficient or dominant negative manner, cause immunodeficiency. Herein we describe four germline heterozygous IKAROS variants affecting its C-terminal dimerization domain by haploinsufficiency, in four unrelated families. Index patients presented with hematologic disease consisting of cytopenias (thrombocytopenia, anemia, neutropenia)/Evans syndrome, and malignancies (T-ALL, Burkitt lymphoma). These mutations are partially or completely deficient to form homo- and hetero-dimers, but do not affect the wild type allele function. Moreover, they alter key mechanisms of IKAROS gene regulation including sumoylation, protein stability, and the recruitment of the nucleosome remodeling and deacetylase complex; none of them affected the N-terminal DNA binding. These C-terminal dimerization mutations are largely associated with hematologic disorders, display dimerization haploinsufficency, incomplete clinical penetrance, and differ from previously reported allelic variants in their mechanism of action. Dimerization mutants contribute to the growing spectrum of IKAROS-associated diseases displaying a genotype-phenotype correlation.

Conflict of interest: No COI declared

COI notes:

Preprint server: No;

Author contributions and disclosures: HSK and SDR designed the project and wrote the manusCript. CCR, SL, JR, AT, WAG, SS, ZJ, EG, KB, TAF, JV and SC were involved in collecting biologic and clinical data from the patients and analyzing data. HSK, SCM, SG performed experiments and analyzed data. JEN and JS performed RNASeq and analyzed data. JEN, JS, RJH, TS performed next generation sequencing and/or analyzed data. MG, MH, LL assists informed consent process and arrange the sample delivery. EG, JR, CCR, and SC provided samples, clinical information and analyzed data.

Non-author contributions and disclosures: No;

Agreement to Share Publication-Related Data and Data Sharing Statement: Emails to the corresponding author

Clinical trial registration information (if any): 


\section{Germline IKAROS dimerization haploinsufficiency causes hematologic cytopenias and malignancies}

Hye Sun Kuehn ${ }^{1 *}$, Julie E. Niemela ${ }^{1 \wedge}$, Jennifer Stoddard ${ }^{1 \wedge}$, Sara Ciullini Mannurita ${ }^{2 \wedge}$, Tala Shahin $^{3,4,5 \wedge}$, Shubham Goel ${ }^{1}$, Mary Hintermeyer ${ }^{6}$, Raul Jimenez Heredia ${ }^{3,4,5}$, Mary Garofalo ${ }^{1}$, Laura Lucas ${ }^{7}$, Smriti Singh ${ }^{8}$, Annalisa Tondo ${ }^{9}$, Zachary Jacobs ${ }^{10}$, William A. Gahl ${ }^{11}$, Sylvain Latour $^{12}$, James Verbsky ${ }^{6}$, John Routes $^{6}$, Charlotte Cunningham-Rundles ${ }^{13}$, Kaan Boztug ${ }^{3,4,5,14}$, Eleonora Gambineri ${ }^{2}$, Thomas A. Fleisher ${ }^{1}$, Shanmuganathan Chandrakasan ${ }^{7}$, and Sergio D. Rosenzweig $^{1 *}$

1. Immunology Service, Department of Laboratory Medicine, Clinical Center, NIH, USA

2. University of Florence, NEUROFARBA Department/Anna Meyer Children's Hospital, Hematology/Oncology Department, Florence, Italy

3. Ludwig Boltzmann Institute for Rare and Undiagnosed Diseases, Vienna, Austria

4. CeMM Research Center for Molecular Medicine of the Austrian Academy of Sciences, Vienna, Austria

5. St. Anna Children's Cancer Research Institute (CCRI), Vienna, Austria

6. Division of Asthma, Allergy and Clinical Immunology, Department of Pediatrics, Medical College of Wisconsin, Milwaukee, WI, USA.

7. Division of Bone Marrow Transplant, Immunedysregulation and Immuno-hematology Program, Aflac Cancer and Blood Disorders Center, Children's Healthcare of Atlanta, Emory University School of Medicine, Atlanta, GA, USA

8. Genetic Counseling Program, Emory School of Medicine, Atlanta, GA, USA 
9. Anna Meyer Children's Hospital, Hematology/Oncology Department, Florence, Italy.

10. Department of Internal Medicine, University of Missouri School of Medicine, Colombia, MO, USA

11. Section on Human Biochemical Genetics, Medical Genetics Branch, National Human

Genome Research Institute, NIH, Bethesda, MD, USA

12. Laboratory of Lymphocyte Activation and Susceptibility to EBV Infection, Inserm UMR

1163, Paris, France.

13. Division of Clinical Immunology, Department of Medicine, Icahn School of Medicine at Mount Sinai, New York, NY, USA

14. Department of Pediatrics and Adolescent Medicine, Medical University of Vienna, Austria;

St Anna Children's Hospital and Children's Cancer Research Institute, Vienna, Austria

$\wedge$ Equal contribution

\section{*Corresponding Authors}

Hye Sun Kuehn, PhD, hyesun.kuehn@nih.gov and Sergio D. Rosenzweig, MD, PhD (Lead author), srosenzweig@cc.nih.gov; Immunology Service, Department of Laboratory Medicine, NIH Clinical Center, Building 10, Room 2C306, 10 Center Drive, MSC1508, Bethesda, MD, USA

Word count:

Text -4867

Abstract - 162

Figures-7

Tables- 2

Reference count -41 


\title{
Key Points
}

- We report IKAROS allelic variants disrupting dimerization of the IKAROS family of transcription factors.

- IKAROS dimerization mutants act through a distinctive mechanism and manifest predominantly as hematologic diseases, with limited infections.

\begin{abstract}
IKAROS is a transcription factor forming homo/hetero-dimers and regulating lymphocyte development and function. Germline mutations affecting IKAROS N-terminal DNA binding domain, acting in a haploinsufficient or dominant negative manner, cause immunodeficiency. Herein we describe four germline heterozygous IKAROS variants affecting its C-terminal dimerization domain by haploinsufficiency, in four unrelated families. Index patients presented with hematologic disease consisting of cytopenias (thrombocytopenia, anemia, neutropenia)/Evans syndrome, and malignancies (T-ALL, Burkitt lymphoma). These mutations are partially or completely deficient to form homo- and hetero-dimers, but do not affect the wild type allele function. Moreover, they alter key mechanisms of IKAROS gene regulation including sumoylation, protein stability, and the recruitment of the nucleosome remodeling and deacetylase complex; none of them affected the N-terminal DNA binding. These C-terminal dimerization mutations are largely associated with hematologic disorders, display dimerization haploinsufficency, incomplete clinical penetrance, and differ from previously reported allelic variants in their mechanism of action. Dimerization mutants contribute to the growing spectrum of IKAROS-associated diseases displaying a genotype-phenotype correlation.
\end{abstract}




\section{Keywords}

Primary immunodeficiency; inborn errors of immunity; transcription factors; cancer susceptibility; penetrance; expressivity; infections 


\section{Introduction}

IKAROS is a hematopoietic, cell-specific zinc finger transcription factor that plays a crucial role in lymphocyte differentiation and development ${ }^{1,2}$. These effects are mediated through its interaction with the nucleosome remodeling deacetylase (Mi-2/NuRD) and Sin3 histone deacetylase complexes, and the Polycomb repressive complex 2 proteins ${ }^{1,3-6}$. The IKAROS family consists of IKAROS/IKZF1, HELIOS/IKZF2, AIOLOS/IKZF3, EOS/IKZF4, and PEGASUS/IKZF5, each of which has multiple isoforms ${ }^{7-9}$. They all contain a conserved Nterminal DNA binding domain (zinc fingers [ZF]1-4) and a C-terminal dimerization domain (ZF5-6). The N-terminal ZFs are required for binding to specific DNA sequences containing the core GGGAA motif, while the C-terminal ZFs mediate homo- and heterodimerization between IKAROS isoforms and other IKAROS family members ${ }^{7}$.

Mouse models have demonstrated that Ikaros is essential for commitment of early hemopoietic progenitors of the $\mathrm{B}$ and $\mathrm{T}$ lymphoid lineages, and mature lymphoid and myeloid cells ${ }^{10,11}$. In humans, somatic IKZFI mutations leading to functional defects or reduced protein expression were originally observed in patients with B-cell precursor acute lymphoblastic leukemia (ALL) and rarely T-cell ALL, and were associated with poor prognosis ${ }^{12-15}$. Moreover, germline heterozygous IKZFI mutations were detected in $0.9 \%$ of all B-ALL, the most common malignancy in children ${ }^{12}$.

Recently, we and others reported germline heterozygous IKZFI allelic variants associated with specific immunological phenotypes. The phenotypes consisted of a common variable immunodeficiency (CVID)-like presentation with progressive B-cell loss, 
hypogammaglobulinemia and antibody dysfunction, along with recurrent and severe bacterial infections; B-ALL susceptibility and autoimmune manifestations were also observed ${ }^{12,16-22}$. These patients carried heterozygous loss-of-function mutations that primarily affected the DNA binding domain of $I K Z F 1$, impairing its function and displaying haploinsufficiency (HI), i.e., the mutant allele did not affect the function of the wildtype (WT) allele. Alternatively, some DNA binding domain loss-of-function mutations acted in a dominant negative (DN) manner, i.e., the mutant allele negatively affected the function of the WT allele. The latter patients presented with more serious clinical and immunological phenotypes, including severe $\mathrm{T}$ cell differentiation and functional defects, as well as absent B cells, mild to severe neutropenia, and eosinopenia. Their clinical findings included susceptibility to Pneumocystis jirovecii pneumonia; recurrent bacterial, viral, and/or fungal infection; and predisposition to T-ALL ${ }^{23}$.

Herein we describe novel missense and nonsense $I K Z F I$ allelic variants in four unrelated families primarily affecting dimerization and acting by a previously unreported mechanism. The affected individuals presented with some distinctive clinical features, including hematopoietic cytopenias presenting as Evans syndrome and hematologic malignancies including T-cell ALL and Burkitt lymphoma; other manifestations were B-cell lymphopenia and hypogammaglobinemia, but recurrent or severe infections were not highly prevalent. Our data demonstrate that dimerization defective (DD) mutants acting by haploinsufficiency can also disrupt sumoylation, protein stability, and binding to histone deacetylase 1 (HDAC1) that alters the recruitment of the nucleosome remodeling and deacetylase (NuRD) complex affecting gene regulation by this transcription factor. These results demonstrate that mutations affecting the dimerization domain, as well as those involving the DNA binding domain, all lead to IKAROS 
dysfunction. Furthermore, each genotype has a unique mechanism of action likely defining the clinical phenotypes in the growing spectrum of defects producing IKAROS-associated diseases. 


\section{Materials and methods}

\section{Patients and samples}

All patients or their guardians provided written informed consent in accordance with the

Declaration of Helsinki under institutional review board-approved protocols of the National Institute of Allergy and Infectious Diseases, NIH. Blood from healthy donors and patients was obtained under approved protocols, which also allowed for the collection and use of patients' family history and pedigrees for publication. All procedures were based on standard of care and established clinical guidelines were followed.

\section{Sequencing}

Selected next-generation sequencing results were confirmed by Sanger sequencing in index cases, as well as in all relatives available. Sanger sequencing, whole exome sequencing (WES), and RNASeq methods are provided in the Supplementary methods.

\section{Protein expression, localization and interaction}

IKAROS protein expression, co-immunoprecipitations, immunofluorescence and EMSA were performed as previously described ${ }^{23}$ and are detailed in the Supplementary methods.

\section{Luciferase reporter assay}

The IKBS1, high affinity IKAROS binding site (TCAGCTTTTGGGAATACCCTGTCA) was used to assess IKAROS binding activity. Luciferase activity was measured using the Dual- 
Luciferase reporter assay system (Promega) according to the manufacturer's instructions.

Additional information is provided in the Supplementary methods.

\section{Statistical Analysis}

Statistical analyses were performed with GraphPad Prism 6.0 (GraphPad). Differences were considered significant when $P<0.05$. 


\section{Clinical histories}

See complete clinical summaries and laboratory results in Supplemental file and Table 1.

Family A (p.R213*)

Patient A.III.1 is a 17-years-old male, healthy until 9 years of age when he was diagnosed with immune thrombocytopenia (ITP). Laboratory evaluation showed mild leukopenia, thrombocytopenia and hypogammaglobulinemia. He did not have a history of recurrent or severe infections. Family history was remarkable for his father (A.II.1) reporting one episode of pneumonia in adulthood, and pernicious anemia.

Family B (p.S427*)

Patient B.II.1 is a 31-year-old male, healthy until 2.5 years of age when he was diagnosed and successfully treated for T-ALL. He remained asymptomatic until 27 years of age when he developed recurrent episodes of watery diarrhea. No severe or recurrent infections were reported. Immune evaluation at age 28 showed hypogammaglobulinemia and non-protective titers to childhood vaccines. Family history was remarkable for his mother (B.I.1) reporting hypothyroidism and type II diabetes.

Family C (p.C467R)

Patient C.III.1 is a 18-year-old female, healthy until 9 years of age when she was diagnosed with ITP. Pre-rituximab treatment laboratory studies demonstrated slightly diminished Ig levels and a poor response to pneumococcal antigens. At age 13, she was diagnosed with Coombs positive, autoimmune hemolytic anemia and relapsing ITP. Family history was remarkable for her sister 
(C.III.2) reporting Hashimoto's disease; her maternal aunt (maternal aunt C.II.3) with childhood onset CVID, and her maternal grandmother (C.I.1) with adult onset specific antibody deficiency (SAD).

Family D (p.R502L)

Patient D.II.1 is a 15-year-old male, healthy until 9 years of age when he was diagnosed and successfully treated for a disseminated Burkitt lymphoma. At age 12, a non-malignant 5-6 cm diameter intra-abdominal lymph node was diagnosed. Soon after, he developed ITP and neutropenia. Family history was unremarkable. 


\section{Results}

IKZF1 mutations, familial segregation, transcription, and protein expression

Four individual germline heterozygous mutations in IKZFI (NM_006060) were identified by WES in each family's index patient, i.e., c.637C >T (p.R213*) in A.III.1, c.1280C >A (p.S427*)

in B.II.1, c.1399T>C (p.C467R) in C.III.1, and c.1505G>T (p.R502L) in D.II.1 (Fig. 1A, B);

results were confirmed by Sanger sequencing. The index patient's mutation was detected in other relatives of all four families (A.I.1, A.II.1, B.I.1, C.I.1, C.II.1, C.II.2, C.II.3, C.III.2 and D.I.1) (Fig. 1A). Amino acids C467 and R502 are conserved through evolution (Fig. 1C). None of these variants are reported in the Genome Aggregation Database (Supplemental table 1).

Mutant allele transcripts were detected in the index patients and mutation-positive family members tested (Fig 2A). IKAROS expression was evaluated in $\mathrm{T}$ and $\mathrm{B}$ cells by flow cytometry using a C-terminus directed antibody aimed to detect both the WT and the missense, but not the C-terminus truncated forms of the protein. In this setting, index patients with missense mutations (C.III.1 and D.II.1) and healthy donors showed comparable IKAROS levels (Fig. 2B). Conversely, patients with nonsense mutations (A.III.1, and B.II.1) demonstrated reduced IKAROS expression as only one copy of the WT protein was expressed and detected (Fig. 2B). When an N-terminus directed antibody aimed to detect the WT and both mutant forms of the protein was tested by western blot, truncated mutant proteins R213* and S427* were discriminated at their predicted molecular weights of $25 \mathrm{kDa}$ and $45 \mathrm{kDa}$, respectively (i.e., lower than the $60 \mathrm{kDa}$ molecular weight of WT (isoform 1) or missense mutated IKAROS) in the nuclear extracts of T-cell blasts of index patients A.III.1 and B.II.1 (Fig. 2C). Since the protein 
expression level of truncated mutants R213* and S427* was lower than WT in T-cell blasts (overexposed blots shown), DD mutant protein stability was evaluated by a cycloheximide chase assay. When compared to each respective cycloheximide-untreated sample, WT IKAROS protein expression was reduced by $32 \%$; whereas DD mutants were 51-89 \% degraded (R213* 72\%, S427* 70\%, C467R 89\%, R502L 51\%, Y462* [laboratory-generated vector lacking ZF5 \& ZF6] 80\%) (Fig. 2D and E). Previously described HI mutant R162Q and DN mutant N159S showed similar degradation levels as WT IKAROS. These results show that, despite their in vitro reduced protein stability that may have contributed to the decreased amount of mutant protein in patients A.III.1 and B.II.1 (Fig. 2C), DD mutants are indeed transcribed and expressed in both primary and transfected cells.

\section{IKAROS homo/heterodimerization}

All four DD mutations are predicted to affect either ZF5 and/or ZF6, which are essential for homo/heterodimerization with IKAROS and its family members. We therefore examined the ability of the mutant proteins to homodimerize with WT IKAROS and heterodimerize with IKAROS family members, AIOLOS and HELIOS. Mutants R213*, S427*, C467R completely failed to bind WT IKAROS; mutant R502L showed partial binding ( 25\% compared to WT/WT binding). Truncated IKAROS mutant proteins R213* and S427* completely failed to bind WT AIOLOS or WT HELIOS; minimal binding $(<5 \%)$ was detected with the C467R mutant, and $\sim 60 \%$ binding was observed with the R502L mutant protein (Fig. 3). These results demonstrate that all four IKAROS DD mutations disrupt homo- and heterodimerization, either completely (R213*, S427* and C467R) or partially (R502L). 
DNA binding and pericentromeric heterochromatin localization

WT or mutant IKAROS proteins were expressed in NIH3T3 cells, known to lack endogenous expression of IKAROS or its family members, for the evaluation of pericentric-heterochromatin (PC-HC) localization ${ }^{9,24,25}$. WT IKAROS exhibited the characteristic punctate staining pattern of PC-HC localization. Complete DD mutants R213*, S427*, Y462* and C467R exhibited a diffuse distribution in the nucleus without PC-HC localization; patial DD mutant R502L showed a punctate staining pattern similar to that of WT (Fig 4A). These data suggests that partial but not completely defective dimerization can support normal PC-HC DNA binding. Co-expressing mutant proteins with WT IKAROS to mimick heterozygosity did not affect WT IKAROS PCHC targeting, ruling out a DN effect. Likewise, known IKAROS HI mutant R162Q did not have a DN effect; however, previously reported DN mutant N159S did affect WT IKAROS PC-HC targeting (Fig. 4B).

EMSA assays were performed to evaluate IKAROS' ability to specifically bind its DNA target sequences. WT IKAROS recognized DNA target baits and bound as monomers, dimers, and multimers, that were discriminated based on their molecular weights. Mutants R213*, S427* and Y462* showed strong monomer but no dimer or multimer binding, suggesting that failed IKAROS homodimerization still allows monomer protein-target binding (Fig. 5A). Mutant C467R showed overall reduced binding to all DNA/IKAROS containing complexes, and mutant R502L showed low to normal binding as a monomer and weak binding as dimers and multimers (Fig. 5A). Previously reported HI and DN mutants showed complete absence of DNA binding as monomers, dimers or multimers. Co-expression of DD mutants with WT IKAROS demonstrated no effect on its DNA binding to target probes, ruling out a DN effect (Fig 5B). 
Gene transcription regulation by IKAROS DD mutations was assed by a luciferase assay (vector carrying the IKAROS consensus sequence, IKBS1). Ectopic expression of WT IKAROS repressed $\sim 60 \%$ of basal transcriptional activity (Fig 5C). Complete dimerization defective mutants $\mathrm{R} 213^{*}, \mathrm{~S} 427^{*}, \mathrm{Y} 462^{*}$ and C467R minimally repressed the basal transcriptional activity; partial DD mutant R502L repressed levels similar to WT IKAROS. When WT and DD IKAROS mutants were co-expressed, luciferase activity was repressed to the levels of WT alone, suggesting no DN effect by the DD mutants. Noteworthy, DNA-binding defective HI mutant R162Q completely failed to repress the basal transcriptional activity but DN mutant N159S repressed the transctiptional activity by $46 \%$, despite its inability to bind to its specific DNA binding sites, highlighting the intrinsic limitations of this type of study (Fig 5A, C). Altogether, as complete DD mutants R213*, S427*, and C467R have lost PC-HC localization (Fig 4A), binding their target sequence as monomers seems insufficient to localize to PC-HC or repress transcription, suggesting that binding as dimers and/or multimers is required for the pericentromeric localization and transcription regulation.

\section{Post-translational modification and transcriptional regulation}

Sumoylation, a post-translational process that involves the conjugation of small ubiquitin-like modifiers (SUMOs, $12 \mathrm{kDa}$ ), is a major regulator of protein functions, including cell-cycling, cell survival, DNA repair, protein stability, nuclear transport, and transcription ${ }^{26}$. IKAROS harbors four SUMO acceptor sites (K58, K240, K425, K459), and its sumoylation disrupts the interaction between IKAROS and co-repressors of the NuRD complex ${ }^{27}$. We detected multiple shifted bands of single and multi-symoylated IKAROS WT protein (Fig. 6A). Complete DD 
mutants (R213*, S427*, C467R, and Y462*) showed markedly reduced sumoylated proteins (Fig. 6A) either by missed sumoylation sites (e.g., R213*, S427*) and/or likely structural/functional defects associated with each particular DD mutation (e.g., C467R, Y462*). Partial DD mutant R502L, and DNA binding defective mutants HI R162Q and DN N159S, did not affect sumoylation. This data suggest that IKAROS dimerization (fully or partially preserved) is necessary for IKAROS sumoylation.

Both the $\mathrm{N}$ - and $\mathrm{C}$-terminal IKAROS regions are associated with the NuRD complex, regulating the repression of transcriptional activity via histone deacetylase (HDAC)-dependent or independent mechanisms. IKAROS sumoylation also affects its interaction with the NuRD complex $^{27}$. Mutants lacking the dimerization domain $\left(\mathrm{R} 213^{*}, \mathrm{~S} 427^{*}, \mathrm{Y} 462^{*}\right)$ showed markedly decreased interaction with HDAC1 (a core subunit of the NuRD complex); missense mutants (C467R, R502L) showed markedly increased HDAC1 binding (Fig. 6B). No HDAC1 binding defects were detected with HI mutant R162Q or DN mutant N159S. When we tested the interaction between IKAROS and the C-terminal binding protein (CtBP), a HDAC-independent corepressor known to associate with IKAROS through a PEDLS motif located at IKAROS Nterminus domain ${ }^{28}$, both truncated and missense IKAROS DD mutants showed similar levels of binding (Supplemental figure 1). This result suggests that IKAROS-HDAC1 interaction is likely independent of transcriptional regulators binding to the N-terminus of IKAROS such as CtBP, and mostly dependent on the structural/functional integrity of IKAROS C-terminal region. These results also suggest that the dysregulated HDAC1 recruitment by DD mutants is unlikely dependent upon PC-HC localization or sumoylation: mutants C467R and R502L, presenting opposite effects on these functions, showed similarly increased HDAC1 binding. Different 
structural/functional defects associated with each particular DD mutation likely determine their dysregulated HDAC1 binding through C-terminus region of the protein.

The effect of the DD variants on gene transcription was evaluated by RNASeq analysis on T-cell blasts, and compared to healthy donors (HD) and patients with DNA binding defective HI (H167R) and DN (N159S) allelic variants (1 of each). Correlation analysis with unsupervised clustering showed that gene expression signatures in all allelic variants clustered together and separated from HD (Fig. 7A). An allelic variant-focused evaluation confirmed that when compared to HD, each mutation type was associated with a particular set of up- and downdysregulated genes: 42 in the DD patients (12 up-, 30 down-regulated), 63 in the DNA binding HI patients (19 up, 44 down) and 534 in the DNA binding DN patients (315 up-, 219 down). A more discrete number of genes was commonly dysregulated among all allelic variants (Fig. 7B and C). Data analysis through the Ingenuity pathway analysis (IPA) showed that the functions related to development of malignant tumor and differentiation of leukemic cell lines were activated in DD patient cells, whereas functions associated with infection, inflammatory response, T cell homeostasis, development and differentiation were not (Fig. 7D and Supplemental figure 2). Interestingly, while malignant tumor-related pathway is largely upregulated in DD patients, less canonical pathways were affected compared to the HI and DN patients, suggesting that the different regulation of genes, at least in part, is associated with different clinical and immunological phenotypes in the three groups of IKAROS allelic variants. To evaluate the IKAROS-specific NuRD and Sin3-related gene transcription, a PCR gene array methodological approach was tested in patients for all known IKAROS allelic variants. Patients carrying DD (complete and partial), HI and DN DNA binding defective variants could be 
discriminated upon analysis. Among the NuRD and Sin3-related gene transcripts, genes in which mutations have been described to be associated with T-ALL and Burkitt lymphoma in the COSMIC database (i.e., CREBBP, NCOR1, NCOR2) were dysregulated in the DD patients. Moreover, known cancer-associated genes (i.e., CHD, MTA, NCOR, HDAC etc.) ${ }^{29-32}$ and genes associated with immune dysregulation or autoimmune diseases (i.e., ARID4A, Histone H4 [HIST4H4, HIST1H4I], MTA2) ${ }^{33-35}$ were also dysregulated in DD patients (Supplemental figure 3). Taken together, these results suggest that DD mutations dysregulate IKAROS function and transcription through a mechanism different from that of DNA binding defective mutations, and a subset of the dysregulated genes are closely associated with the hematologic manifestations presented by the DD patients.

Baseline lymphocyte phenotype and immune functions were evaluated in the DD patients (Table 1) and results were compared to previously reported allelic variants. The overall B-cell and Tcell immunophenotype was closer to DNA binding defective HI patients (i.e., progressive B cell lymphopenia, elevated $\mathrm{CD} 8^{+} \mathrm{T}$ cells) than that of $\mathrm{DN}$ patients (i.e., early absence of $\mathrm{B}$ cells, severe T cell maturation and functional defects) ${ }^{16,23,36}$. However, distinctive immunophenotypic features could also be identified between DD and HI allelic variants. Dimerization defects displayed a more limited impact on B cells than the other allelic variants as B cells were $\leq 2 \%$ in $1 / 13(7.6 \%)$ DD patients, compared to $16 / 26(61.5 \%)$ in HI patients, and 7/7 (100\%) in DN patients ${ }^{16,23}$. Moreover, $\mathrm{CD}^{+} \mathrm{T}$ cells were increased in $14 / 26(54 \%)$ HI patients, but this feature was less prevalent in the DD $(3 / 13,23 \%)$ or DN $(2 / 7,29 \%)$ cases studied. Furthermore, whereas patients carrying DN IKAROS mutations had defects in memory T-cell differentiation and impaired T-cell activation and proliferation, all four DD index patients had normal percentages 
of memory T cells and normal T-cell proliferation (Table 1 and Supplemental figure 4). When B cell function was tested in the four index patients, BCR or CD40L-induced B-cell proliferation was comparable to the normal controls in three (A.III.1, C.III.1, D.II.1) and slightly/moderately decreased in one patient (B.II.1). To further evaluate B cell functions, we tested immunoglobulin secretion from naïve B cells and total PBMCs. While markedly decreased IgG generation was observed in index patients B.II.1 and C.III.1 both in naïve B cells and total PBMCs (A.III.1 was not tested due to limited sample availability), slightly low and normal levels of IgG secretion were detected in patient D.II.1's naïve B cells and PBMCs, respectively (Supplemental figure 5). This result correlates with the serum immunoglobulin levels in index patients (B.II.1, C.III.1, and D.II.1), and explains the milder impact of B cell function in family D. Interestingly, variable results were observed among family members carrying the same mutations, reinforcing the variable penetrant and expressivity impact of IKZF1 DD mutants. 


\section{Discussion}

We report thirteen individuals in four unrelated families carrying four novel germline heterozygous $I K Z F I$ mutations primarily affecting dimerization. We demonstrated that DD mutants were completely or partially incapable of binding to WT IKAROS, AIOLOS and HELIOS. Besides the dimerization defect, several other downstream functions were also affected. These mutant proteins could not bind to their consensus sequences in target DNA as dimers or multimers, but two of them (i.e., R213* and S427*) were still able to bind as monomers, and all but mutant R502L failed to localize to PC-HC where IKAROS recruits its target genes for transcription regulation. Noteworthy, the four mutants showed a range of impact degrees depending on the function evaluated, being the nonsense mutations the most deleterious and R502L the least, based on the experiments performed. Under a structural/protein modeling analysis it is predicted that the polar basic to nonpolar missense change associated with mutation R502L within the alpha helix of the IKAROS C2H2-6 domain, may abolish cation-pi interactions thereby destabilizing the IKAROS $\mathrm{C} 2 \mathrm{H} 2$ alpha helix and disrupting the homodimerization interface as the other DD mutants also do (data not shown). On a genotype/phenotype perspective, the R502L dychotomy between reduced biologic impact with still an aggressive clinical presentation is likely a matter of functional threshold (or gene dosage) associated with the intrinsic biology of DD haploinsufficiency. The performance of R502L, as seen with the other DD mutants, falls under the haploinsufficiency range of activity for multiple IKAROS functions. Once this threshold is trespassed (either by a little or a lot), the function seems compromised and results in a biologic, and in its turn, clinical phenotype. More difficult to define is the exact haploinsufficiency range or threshold for each IKAROS function, particularly 
considering this transcription factor includes at least 17 isoforms acting by homo/heterodimerization with other family members. Nonetheless, mutant protein R502L was still able to generate a robust biologic and clinical impact, despite a reduced functional effect of PCHC binding and sumoylation. The R502L mutant, associated with hematologic cytopenias and malignancy, showed reduced IKAROS homo/heterodimerization ( $25 \%$ and $\sim 60 \%$ of WT, respectively), decreased protein stability, affected IKAROS dimer/multimer binding to DNA consensus sequences, dysregulated general and NuRD/Sin3-related specific gene transcription and HDAC1 binding.

In fact, all of the DD mutants altered all these functions, highlighting their common underlying pathophysiologic mechanisms. Moreover, these features also distinguish them from the HI and DN allelic variants that share defective DNA binding, but do not display any of the DD-related defects mentioned above (Table 2).

Post-translational modification of transcription factors has been proprosed to modulate activation or repression of numerous genes during lymphocyte development ${ }^{27,37}$. IKAROS is required to facilitate chromosome accessibility on target genes, where it recruits the NuRD complex for gene expression regulation. Sumoylation, a post-translational change affecting IKAROS, has been shown to interfere with the recruitment of gene transcription co-repressors ${ }^{27}$. Impaired DNA binding of IKAROS is associated with release of the NuRD complex from IKAROS target genes. Released NuRD complexes cause lymphocyte maturation arrest which promotes leukemogenesis ${ }^{38}$. Our study shows that germline mutants that lack IKAROS dimerization domain $\left(\mathrm{R} 213^{*}, \mathrm{~S} 427^{*}\right)$ result in a marked reduction of sumoylation and HDAC1 binding. These findings indicate that IKAROS' N-terminal domain is involved in recruitment of HDAC1 
but depends on the C-terminal domain to be functionally intact (Fig 6A and B). In contrast, missense mutants that maintain the IKAROS dimerization domain but still demonstrate defective dimerization (C467R and R502L) show markedly increased binding to HDAC1, suggesting that the C-terminal domain can recruit more HDAC1 when not occupied by IKAROS family members. To address how dimerization defects and alteration of HDAC1 recruitment affect transcription activity, we tested luciferase activity using a pGL4.11 vector containing IKBS1 repeats. While complete DD mutants R213*, S427*, C467R, and Y462*, and HI mutant R162Q failed to repress the transcription activity, partial DD mutant R502L did not show any defect in repression of transcription activity. This shows that binding as polymers is more important for the transcription repression than the alteration of NuRD/HDAC1 complex recruitment, which was increased by C467R and R502L but decreased by R213* and S427*. Based on our experience with this technique, we acknowledge that luciferase results using an extrachromosomal reporter plasmid containing a small part of the IKAROS binding region may not accurately reproduce long distance interactions that may be essential for IKAROS function, chromatin assembly or recruitment of NuRD complex. Therefore, the detailed mechanisms by which altered NuRD complex recruitment of DD mutants affect transcription repression need to be further studied for full elucidation.

When we assessed gene level transcription by RNASeq, we found that all IKAROS allelic variants tested (complete and partial DD mutants and DNA binding defective HI and DN mutants) shared an abnormal gene expression pattern. However, comparing HD vs. each IKAROS mutation-type determined that each allelic variant dysregulated a unique set of genes. IPA pathway analysis revealed that while functions associated with malignant tumor 
development were largely dysregulated in DD and DN patients, functions related with T cell development and differentiation were preferentially dysregulated in HI and DN patients. These results suggest a corelation between genotypes and clinical/immunological phenotypes, as hematologic malignancies were more prevlent in DD (2/13) and DN (1/8) patients when compared to HI patients (3/59), wheras abnormal T cell lineage differentiation and/or function were more frequently reported in DN (8/8), and HI (13/26) patients but were not that prevalent in DD mutation carriers (3/13) patients analyzed ${ }^{16,36}$. Moreover, we performed an IKAROSassociated NuRD and Sin3-related gene transcription evaluation using a different technical approach to achieve a more in depth assessment. This PCR gene array-based analysis further discriminated the mutation types at the transcriptomic level and linked the DD mutants to the patients' clinical presentations (hematologic cytopenias due to immunedysregulation and malignancies) (Fig 7 and Supplemental figure 3). Our data show that DD mutations affect the chromatin remodeling complex of particular genes and modify the chromatin landscape, likely leading to oncogenesis and a break in immunological tolerance highly compatible with the clinical phenotype described in our patients.

In terms of clinical presentations, four of thirteen mutation-positive individuals reported herein were asymptomatic (A.I.1, C.II.1, C.II.2 and D.I.1), and one (B.I.1) presented with hypothyroidism and type 2 diabetes, symptoms questionably related to the IKAROS defect. On the other hand, two presented with tissue-specific autoimmunity, i.e., pernicious anemia in A.II.1 and Hashimoto's disease in C.III.2, and two presented with recurrent infections associated with either late onset specific antibody deficiency (C.I.1) or early onset CVID-like disease (C.II.3). Interestingly, the four index cases (A.III.1, B.II.1, C.III.1, and D.II.1) all presented with hematologic cytopenias or malignancies but no, or very limited, history of infections. 
Manifestations in the index patients started during their first decade of life either as T-ALL, Burkitt lymphoma or cytopenias resembling Evans syndrome, a rare autoimmune disorder of AIHA, ITP, and/or autoimmune neutropenia. A recent study demonstrated that 49 of 80 pediatric patients with Evans syndrome had germline variants in primary immunodeficiency (PID)causing genes ${ }^{39}$. Although that study did not provide biologic validation for the variants found, 29 were linked to muations that had been previously proven deleterious, while 20 were not. Among the latter, two patients with $I K Z F 1$ and one with $I K Z F 2$ mutations presented with Evans syndrome during childhood ${ }^{39}$. Our work not only reinforces the genetic and clinical relationship between IKAROS and Evans syndrome as recently reported, but also provides biologic validation of this genotype-phenotype correlation describing a novel dimerization defective mechanism for IKAROS-associated diseases. Other germline heterozygous mutations predicted to negatively affect IKAROS' dimerization domain (K286*, D186fs, M306*, and C394*) have been recently published ${ }^{12,21}$. Although the intrinsic dimerization defect and mechanism of action were not part of the scope of those manuscripts, these mutants appeared to exhibit incomplete clinical penetrance and were mainly associated with hematologic manifestations (i.e., B-ALL and different degrees of B-cell deficiency); recurrent infections likely occurred in only one of those $\operatorname{cases}^{12,21}$.

All germline heterozygous $I K Z F 1$ allelic variants reported so far (i.e., HI, DN) and herein (i.e., DD), are associated with certain clinical phenotypes. While patients with DN mutations present with a T- and B-cell CID phenotype mainly characterized by opportunistic infections $(7 / 7)^{23}$, patients carrying HI mutations present primarily with a CVID picture of increased susceptibility to B-cell immunity-controlled infections $(\sim 60 \%)^{16-22,40}$; patients with DD mutations, most 
typically present with hematologic dyscracias (38\%, 5/13; cytopenias in 4, malignancies in 2). Although the clinical presentations of the three allelic variants cannot be completely differentiated from each other, they largely segregate with a particular pathophysiologic mechanism (HI, DN or DD) affecting IKAROS function.

Similar to patients carrying HI defects but in contrast to those with DN allelic variants, we detected virtually asymptomatic DD mutation-positive relatives of the index cases in at least three of the four extended families evaluated. Some of the asymptomatic relatives showed signs that could be interpreted as immunologic penetrance despite the lack of symptoms (e.g., B.I.1, had slightly diminished IgG levels; C.II.1 had reduced switched and non-switched meomory B cells). This type of presentation with incomplete immunologic and/or clinical penetrance is common in autosomal dominant PIDs ${ }^{16,41}$. Moreover, although all index cases clinically manifested symptoms within the first decade of life, late onset disease rather than non-clinical penetrance cannot be ruled out

In summary, germline heterozygous IKAROS dimerization defects acting through haploinsufficiency, work via a unique pathophysiologic mechanism and may manifest during childhood with hematologic diseases consisting of cytopenias (ITP, AIHA and/or neutropenia)/Evans syndrome and malignancies (T-ALL and Burkitt lymphoma) with limited infections and what appears to be incomplete clinical penetrance. These findings, together with previous reports of DNA binding haploinsufficiency $(\mathrm{HI})$ mutations presenting primarily as CVID-like disease and dominant negative (DN) defects presenting as CID, expand the genotype- 
phenotype spectrum of IKAROS-associated diseases with underlying novel pathophysiology mechanisms and distinctive immunological and clinical features. 


\section{Acknowledgments}

We thank the patients and their families for their contributions to the study. These studies were supported by the Intramural Research Program, NIH Clinical Center, US National Institutes of Health (NIH). The content of this article does not necessarily reflect the views or policies of the Department of Health and Human Services, nor does mention of trade names, commercial products, or organizations imply endorsement by the U.S. government.

\section{Author contributions}

HSK and SDR designed the project and wrote the manuscript. CCR, SL, JR, AT, WAG, SS, ZJ, $\mathrm{EG}, \mathrm{KB}, \mathrm{TAF}, \mathrm{JV}$ and SC were involved in collecting biologic and clinical data from the patients and analyzing data. HSK, SCM, SG performed experiments and analyzed data. JEN and JS performed RNASeq and analyzed data. JEN, JS, RJH, TS performed next generation sequencing and/or analyzed data. MG, MH, LL assists informed consent process and arrange the sample delivery. EG, JR, CCR, and SC provided samples, clinical information and analyzed data.

\section{Disclosure of Conflicts of Interest}

The authors declare no competing financial interests. 


\section{References}

1. Georgopoulos K, Bigby M, Wang JH, et al. The Ikaros gene is required for the development of all lymphoid lineages. Cell. 1994;79(1):143-156.

2. Georgopoulos K. Haematopoietic cell-fate decisions, chromatin regulation and ikaros. Nat Rev Immunol. 2002;2(3):162-174.

3. Koipally J, Georgopoulos K. A molecular dissection of the repression circuitry of Ikaros. J Biol Chem. 2002;277(31):27697-27705.

4. Oravecz A, Apostolov A, Polak K, et al. Ikaros mediates gene silencing in T cells through Polycomb repressive complex 2. Nat Commun. 2015;6:8823.

5. Kim J, Sif S, Jones B, et al. Ikaros DNA-binding proteins direct formation of chromatin remodeling complexes in lymphocytes. Immunity. 1999;10(3):345-355.

6. McDonel P, Costello I, Hendrich B. Keeping things quiet: roles of NuRD and Sin3 corepressor complexes during mammalian development. Int J Biochem Cell Biol. 2009;41(1):108116.

7. Perdomo J, Holmes M, Chong B, Crossley M. Eos and pegasus, two members of the Ikaros family of proteins with distinct DNA binding activities. J Biol Chem. 2000;275(49):38347-38354.

8. Morgan B, Sun L, Avitahl N, et al. Aiolos, a lymphoid restricted transcription factor that interacts with Ikaros to regulate lymphocyte differentiation. EMBO J. 1997;16(8):2004-2013.

9. Hahm K, Cobb BS, McCarty AS, et al. Helios, a T cell-restricted Ikaros family member that quantitatively associates with Ikaros at centromeric heterochromatin. Genes Dev. 1998;12(6):782-796.

10. Heizmann B, Kastner P, Chan S. The Ikaros family in lymphocyte development. Curr Opin Immunol. 2018;51:14-23.

11. Francis OL, Payne JL, Su RJ, Payne KJ. Regulator of myeloid differentiation and function: The secret life of Ikaros. World J Biol Chem. 2011;2(6):119-125.

12. Churchman ML, Qian M, Te Kronnie G, et al. Germline Genetic IKZF1 Variation and Predisposition to Childhood Acute Lymphoblastic Leukemia. Cancer Cell. 2018;33(5):937-948 e938.

13. Tran TH, Harris MH, Nguyen JV, et al. Prognostic impact of kinase-activating fusions and IKZF1 deletions in pediatric high-risk B-lineage acute lymphoblastic leukemia. Blood Adv. 2018;2(5):529-533.

14. Mullighan CG, Miller CB, Radtke I, et al. BCR-ABL1 lymphoblastic leukaemia is characterized by the deletion of Ikaros. Nature. 2008;453(7191):110-114.

15. Kastner P, Dupuis A, Gaub MP, Herbrecht R, Lutz P, Chan S. Function of Ikaros as a tumor suppressor in B cell acute lymphoblastic leukemia. Am J Blood Res. 2013;3(1):1-13.

16. Kuehn HS, Boisson B, Cunningham-Rundles C, et al. Loss of B Cells in Patients with Heterozygous Mutations in IKAROS. N Engl J Med. 2016;374(11):1032-1043.

17. Hoshino A, Okada S, Yoshida K, et al. Abnormal hematopoiesis and autoimmunity in human subjects with germline IKZF1 mutations. J Allergy Clin Immunol. 2017;140(1):223-231.

18. Bogaert DJ, Kuehn HS, Bonroy C, et al. A novel IKAROS haploinsufficiency kindred with unexpectedly late and variable B-cell maturation defects. J Allergy Clin Immunol. 2018;141(1):432-435 e437.

19. Sriaroon P, Chang Y, Ujhazi B, et al. Familial Immune Thrombocytopenia Associated With a Novel Variant in IKZF1. Front Pediatr. 2019;7:139. 
20. Van Nieuwenhove E, Garcia-Perez JE, Helsen C, et al. A kindred with mutant IKAROS and autoimmunity. J Allergy Clin Immunol. 2018;142(2):699-702 e612.

21. Eskandarian Z, Fliegauf M, Bulashevska A, et al. Assessing the Functional Relevance of Variants in the IKAROS Family Zinc Finger Protein 1 (IKZF1) in a Cohort of Patients With Primary Immunodeficiency. Front Immunol. 2019;10:568.

22. Dieudonne Y, Guffroy A, Vollmer O, Carapito R, Korganow AS. IKZF1 Loss-ofFunction Variant Causes Autoimmunity and Severe Familial Antiphospholipid Syndrome. J Clin Immunol. 2019;39(4):353-357.

23. Boutboul D, Kuehn HS, Van de Wyngaert Z, et al. Dominant-negative IKZF1 mutations cause a T, B, and myeloid cell combined immunodeficiency. J Clin Invest. 2018;128(7):30713087.

24. Cobb BS, Morales-Alcelay S, Kleiger G, Brown KE, Fisher AG, Smale ST. Targeting of Ikaros to pericentromeric heterochromatin by direct DNA binding. Genes Dev. 2000;14(17):2146-2160.

25. Molnar A, Wu P, Largespada DA, et al. The Ikaros gene encodes a family of lymphocyte-restricted zinc finger DNA binding proteins, highly conserved in human and mouse. J Immunol. 1996;156(2):585-592.

26. Gill G. SUMO and ubiquitin in the nucleus: different functions, similar mechanisms? Genes Dev. 2004;18(17):2046-2059.

27. Gomez-del Arco P, Koipally J, Georgopoulos K. Ikaros SUMOylation: switching out of repression. Mol Cell Biol. 2005;25(7):2688-2697.

28. Koipally J, Georgopoulos K. Ikaros interactions with CtBP reveal a repression mechanism that is independent of histone deacetylase activity. $J$ Biol Chem. 2000;275(26):19594-19602.

29. Kumar R, Wang RA. Structure, expression and functions of MTA genes. Gene. 2016;582(2):112-121.

30. Moreno DA, Scrideli CA, Cortez MA, et al. Differential expression of HDAC3, HDAC7 and HDAC9 is associated with prognosis and survival in childhood acute lymphoblastic leukaemia. Br J Haematol. 2010;150(6):665-673.

31. Li W, Mills AA. Architects of the genome: CHD dysfunction in cancer, developmental disorders and neurological syndromes. Epigenomics. 2014;6(4):381-395.

32. Battaglia S, Maguire O, Campbell MJ. Transcription factor co-repressors in cancer biology: roles and targeting. Int J Cancer. 2010;126(11):2511-2519.

33. Lu X, Kovalev GI, Chang H, et al. Inactivation of NuRD component Mta2 causes abnormal T cell activation and lupus-like autoimmune disease in mice. J Biol Chem. 2008;283(20):13825-13833.

34. Chen R, Kang R, Fan XG, Tang D. Release and activity of histone in diseases. Cell Death Dis. 2014;5:e1370.

35. Wu MY, Eldin KW, Beaudet AL. Identification of chromatin remodeling genes Arid4a and Arid4b as leukemia suppressor genes. J Natl Cancer Inst. 2008;100(17):1247-1259.

36. Nunes-Santos CJ, Kuehn HS, Rosenzweig SD. IKAROS Family Zinc Finger 1Associated Diseases in Primary Immunodeficiency Patients. Immunol Allergy Clin North Am. 2020;40(3):461-470.

37. Popescu M, Gurel Z, Ronni T, et al. Ikaros stability and pericentromeric localization are regulated by protein phosphatase 1. J Biol Chem. 2009;284(20):13869-13880. 
38. Zhang J, Jackson AF, Naito T, et al. Harnessing of the nucleosome-remodelingdeacetylase complex controls lymphocyte development and prevents leukemogenesis. Nat Immunol. 2011;13(1):86-94.

39. Hadjadj J, Aladjidi N, Fernandes H, et al. Pediatric Evans syndrome is associated with a high frequency of potentially damaging variants in immune genes. Blood. 2019.

40. Goldman FD, Gurel Z, Al-Zubeidi D, et al. Congenital pancytopenia and absence of B lymphocytes in a neonate with a mutation in the Ikaros gene. Pediatr Blood Cancer. 2012;58(4):591-597.

41. Conley ME, Casanova JL. Discovery of single-gene inborn errors of immunity by next generation sequencing. Curr Opin Immunol. 2014;30:17-23. 


\section{Figure and table legends}

Figure 1. Genetics and pedigrees of families with IKZFI mutations. (A) Segregation of the IKZF 1 mutations and clinical and immunological phenotypes. Squares and circles indicate male and female family members, respectively. Question mark indicates an unscreened individual. (B) Schematic presentation of the structure of IKAROS isoform 1 (NM_006060). Dark gray indicates the zinc fingers $(\mathrm{ZF})$ and arrows indicate the site of the mutations. Numbers indicate amino acid location. Previously reported germline IKAROS mutations in CVID or CID patients are indicated below the domain. Blue color indicates haploinsufficient mutations (DNA binding defective mutations and loss of one IKZFI allele); dominant negative mutations are shown in red; dimerization defective mutations are shown in green; gray color indicates the variants whose function are unclear. (C) Sequence conservation of ZF5 and ZF6 in IKAROS. The mutated amino acid sites found in Families C and D (C467 and R502, respectively) are indicated in the green box.

Figure 2. IKAROS transcripts and protein expression in patients (A) The chromatograms show the sequence of the indicated heterozygous mutation in cDNA prepared from PBMCs. WT indicates wild type of IKAROS's reference sequence. Arrows indicate the site of mutations. (B) IKAROS protein expression levels were tested in T and B cells from PBMCs from index patients and a paired healthy donor control (HD). (C) IKAROS expression in nuclear extracts of T cell blasts. Triangles indicate R213* and S427* mutant protein. Bottom blots were overexposed to visualize the low levels of truncated IKAROS protein (R213* and S427*). Data shown are representative of two independent experiments. (D, E) HEK293T cells were transfected with a vector expressing IKAROS WT or mutant. After 24 hours, cells were treated with cycloheximide 
(CHX, $20 \mu \mathrm{g} / \mathrm{ml}$ ) for further $24 \mathrm{~h}$. Whole cell lysates were prepared and analyzed by immunoblot analysis using HA antibodies to test IKAROS expression. Vinculin was used as a loading control. The relative IKAROS protein stability was calculated by dividing CHX treated sample by untreated sample (X100) after normalization with Vinculin to show the remaining protein amount after CHX treatment. Data are mean value \pm SEM of 3-4 independent experiments. Data (WT vs. each mutant) were analyzed using unpaired $t$-test utilizing the GraphPad Prism software. $* p<0.05$.

Figure 3. Impaired interaction of mutant protein with the IKAROS family. (A-C) 293T cells were transfected with Flag-tagged wild type (WT) IKAROS, AIOLOS, HELIOS and HA-tagged IKAROS WT or mutants (R213*, S427*, C467R, R502L, Y462* [a laboratory-generated mutant with deletion of ZF5 and 6]). EV indicates empty vector control. Immunoprecipitations were performed using anti-Flag antibodies. Western blot analysis of the IP samples with anti-HA and anti-Flag or AIOLOS or HELIOS antibodies is shown. $5 \%$ of the total volumes of the whole cellular lysates used for each IP reaction were loaded as input controls. Data shown are representative of 3 independent experiments. Representative densitometry result of immunoprecipiated HA-IKAROS was performed using ImageStudio.

Figure 4. Pericentromeric targeting of the mutant IKAROS. (A-B) NIH3T3 cells were transfected with a HA-tagged WT or mutant expression vector alone (A) or together with Flagtagged WT IKAROS (B). Cells were labeled with anti-HA or together with anti-Flag antibodies, followed by Alexa 488-conjugated (green) and Alexa 568-conjugated (red) secondary antibodies. Cells were visualized by using a ZOE fluorescence microscope (original magnification is X175). 
Data shown are representative of 3 independent experiments. The scale bar indicates $25 \mu \mathrm{m}$. HI and DN indicate DNA binding defective haploinsufficient mutation and dominant negative mutation, respectively.

Figure 5. DNA binding and transcription activity of the mutant IKAROS protein. (A-B) EMSA assays were performed using nuclear extracts from HEK293T cells transfected with indicated IKAROS mutation alone (A) or together with WT IKAROS (B). Numbers indicates the ratio of amount of plasmid DNA used for the co-transfection. The nuclear extracts were allowed to bind to two different IKAROS probes: IK-bs1, an IKAROS consensus binding sequence and $\gamma$-Sat 8 , a sequence from the pericentromeric region of human Chromosome 8. IKAROS containing complexes are indicated with arrows. Triangles indicate mutant IKAROS protein binding to the DNA as a monomer. Data shown are representative of 3 independent experiments. (C). Four repeats of IKBS1 were inserted into the pGL4.11 vector (pGL4.11-IKBS1) and co-transfected with pcDNA3-HA IKAROS wt or mutants and pRL-TK (Renilla luciferase) as indicated. Twenty hours later, cells were lysed and luciferase activity was measured using the DualLuciferase reporter assay system. The firefly luciferase activity was normalized to the Renilla luciferase activity and then the results were normalized to the empty vector control. Each experiment was carried out in duplicate. Data are means \pm SEM from three independent experiments.

Figure 6. Sumoylation of IKAROS WT and mutant. (A) HEK293T cells were co-transfected with GFP-sumo1 and HA-tagged IKAROS WT or mutant. Protein extracts were immunoprecipitated with anti-HA antibodies, and probed with anti-Sumo1 antibodies to see the 
sumoylation, and anti-HA antibodies to see the immunoprecipitated IKAROS. Arrows near 100$200 \mathrm{kDa}$ indicate single or multiple sumoylated IKAROS protein. (B) HEK293T cells were cotransfected with Flag-tagged IKAROS WT or mutant and HA-tagged HDAC1. Protein lysates were immunoprecipitated with antibodies to the Flag epitope. Western blot analysis of the IP samples with anti-HA (for HDAC1) and anti-Flag (for IKAROS) antibodies is shown. 5\% of the total volumes of the whole cellular lysates used for IP reactions were loaded as input controls. Data shown are representative of 3 independent experiments.

Figure 7. Correlation analysis of targeted RNA-seq data on T-cell blasts from healthy donor (HD) controls $(\mathrm{n}=5)$ and patients with DD, HI, and DN mutations. RNASeq was performed using RNA extracted from enriched blasted T cells. Scale bar indicates Pearson correlation coefficient for variance stabilized data for differentially expressed mRNA. (B) Venn diagram analysis comparing lists of differentially expressed genes for each IKAROS study group [i.e., DD (n=4), HI ( $n=1)$, DN (n=1)] vs. HD controls ( $n=5)$. (C) Table of differentially expressed genes for the DD study group only and differentially expressed genes common among groups. Genes overexpressed compared to HD controls are in red text; genes underexpressed compared to HD controls are in blue text. (D) IPA Diseases and Functions Analysis heatmap showing a comparison of the predicted effected cellular processes and biological functions based on gene expression. The activation $\mathrm{z}$-score represents the bias in gene regulation that predicts whether the biological function exists in an activated (red) or inactivated (blue) state. 


\begin{tabular}{|c|c|c|c|c|c|c|c|c|c|c|c|c|c|c|}
\hline $\begin{array}{l}\text { ID } \\
\text { Mutation }\end{array}$ & $\begin{array}{l}\text { A.I.1 } \\
\text { (Grandm } \\
\text { a) } \\
\text { p.R213* }\end{array}$ & $\begin{array}{l}\text { A.II.1 } \\
\text { (Father) } \\
\text { p.R213* }\end{array}$ & $\begin{array}{l}\text { A.III.1 } \\
\text { (Index Pt) } \\
\text { p.R213* }\end{array}$ & $\begin{array}{l}\text { B.I.1 } \\
\text { (Mother) } \\
\text { p.S427* }\end{array}$ & $\begin{array}{l}\text { B.II.1 } \\
\text { (Index Pt) } \\
\text { p.S427* }\end{array}$ & $\begin{array}{l}\text { C.I.1 } \\
\text { (Grandma) } \\
\text { p.C467R }\end{array}$ & $\begin{array}{l}\text { C.II.1 } \\
\text { (Mother } \\
\text { ) } \\
\text { p.C467 } \\
\text { R }\end{array}$ & $\begin{array}{l}\text { C.II.2 } \\
\text { (Aunt) } \\
\text { p.C467R }\end{array}$ & $\begin{array}{l}\text { C.II.3 } \\
\text { (Aunt) } \\
\text { p.C467R }\end{array}$ & $\begin{array}{l}\text { C.III.1 } \\
\text { (Index Pt) } \\
\text { p.C467R }\end{array}$ & $\begin{array}{l}\text { C.III.2 } \\
\text { (Sister) } \\
\text { p.C467R }\end{array}$ & $\begin{array}{l}\text { D.I.1 } \\
\text { (Father) } \\
\text { p.R502L }\end{array}$ & $\begin{array}{l}\text { D.II.1 } \\
\text { (Index Pt) } \\
\text { p.R502L }\end{array}$ & $\begin{array}{l}\text { Reference } \\
\text { (\% of total } \\
\text { lymphocytes) }\end{array}$ \\
\hline Age and gender & $74 y, F$ & $48 \mathrm{y}, \mathrm{M}$ & $17 \mathrm{y}, \mathrm{M}$ & $74 y, F$ & $31 \mathrm{y}, \mathrm{M}$ & $66 \mathrm{y}, \mathrm{F}$ & $44 y, F$ & $36 y, F$ & $38 \mathrm{y}, \mathrm{F}$ & $18 \mathrm{y}, \mathrm{F}$ & $21 \mathrm{y}, \mathrm{F}$ & $50 \mathrm{y}, \mathrm{M}$ & $15 \mathrm{y}, \mathrm{M}$ & \\
\hline Age at onset & & & 9y/ITP & & $2.5 \mathrm{y} / \mathrm{T}-\mathrm{ALL}$ & & & & & 9y/ITP & & & 9y/Burkitt lymphoma & \\
\hline \multicolumn{15}{|c|}{ Lymphocyte phenotyping } \\
\hline CD3 T (ALC) & 812 & 1384 & 970 & 797 & 1348 & $2510(\mathrm{H})$ & 1196 & 1821 & 1004 & 1394 & 1556 & 2095 & $4181(\mathrm{H})$ & 714-2266 言 \\
\hline CD3 T (\%) & 81.2 & $87.6(\mathrm{H})$ & $85.8(\mathrm{H})$ & 57 (L) & $89.3(\mathrm{H})$ & $91.6(\mathrm{H})$ & $\begin{array}{l}87.3 \\
(\mathrm{H})\end{array}$ & 80.2 & $85.8(\mathrm{H})$ & $91.1(\mathrm{H})$ & 77.4 & 77.6 & $88.2(\mathrm{H})$ & 60-83.7 \\
\hline CD4 T (ALC) & $346(\mathrm{~L})$ & $272(\mathrm{~L})$ & 421 & 558 & 477 & 1121 & 523 & 742 & 580 & 915 & 824 & 1450 & $2176(H)$ & $359-1565$ \\
\hline CD4 T (\%) & 34.7 & $17.2(\mathrm{~L})$ & 37.3 & 39.9 & $31.6(\mathrm{~L})$ & 40.9 & 38.2 & 32.7 & 49.6 & 59.8 & 41 & 53.7 & 45.9 & $31.9-62.2$ \\
\hline $\begin{array}{l}\text { CD4+CD62L+CD45 } \\
\text { RA+(\%) }\end{array}$ & n.d. & $3.8(\mathrm{~L})$ & 11.6 & n.d. & $3.4(\mathrm{~L})$ & $3.2(\mathrm{~L})$ & 7.7 & $4.9(\mathrm{~L})$ & 14.2 & 20.4 & 8.5 & 18.2 & 25.6 & $\begin{array}{ll}7.6-37.7 & \\
& 0 \\
& 0\end{array}$ \\
\hline $\begin{array}{l}\text { CD4+CD62L+CD45 } \\
\text { RA- }(\%)\end{array}$ & n.d. & $10.2(\mathrm{~L})$ & 21.5 & n.d. & 24.7 & $34(\mathrm{H})$ & 23 & 25 & $31.3(\mathrm{H})$ & $33.9(\mathrm{H})$ & 25.4 & 22.8 & 15.1 & $10.4-30.7$ \\
\hline $\begin{array}{l}\text { CD4+CD62L- } \\
\text { CD45RA- (\%) }\end{array}$ & n.d. & 3.1 & 4 & n.d. & 3.5 & 3.7 & 6.8 & 2.7 & 4 & 5.2 & 6.6 & 11.7 & 4.6 & $2.3-15.6$ \\
\hline $\begin{array}{l}\text { CD4+CD62L- } \\
\text { CD45RA+ (\%) }\end{array}$ & n.d. & 0.2 & 0.3 & n.d. & 0 & 0 & 0.6 & 0 & 0.1 & 0.3 & 0.5 & 1.1 & 0.6 & $0-1.5$ \\
\hline CD8 T (ALC) & 441 & $1063(\mathrm{H})$ & 483 & 230 & 808 & $1145(\mathrm{H})$ & 564 & 826 & 335 & 412 & 607 & 508 & $1673(\mathrm{H})$ & $178-853$ \\
\hline CD8 (\%) & $44.1(\mathrm{H})$ & $67.3(\mathrm{H})$ & $42.7(\mathrm{H})$ & 16.5 & $53.5(\mathrm{H})$ & $41.8(\mathrm{H})$ & $\begin{array}{l}41.2 \\
(\mathrm{H})\end{array}$ & $36.4(\mathrm{H})$ & 28.6 & 26.9 & 30.2 & 18.8 & $35.3(\mathrm{H})$ & $1 1 . 2 - 3 4 . 8 \longdiv { \emptyset }$ \\
\hline $\begin{array}{l}\mathrm{CD} 8+\mathrm{CD} 62 \mathrm{~L}+\mathrm{CD} 45 \\
\mathrm{RA}+(\%)\end{array}$ & n.d. & $26.8(\mathrm{H})$ & $20.7(\mathrm{H})$ & n.d. & $22(\mathrm{H})$ & 18.8 & 11.3 & 16.2 & 16.4 & $20.2(\mathrm{H})$ & 16 & 7.2 & $26.2(\mathrm{H})$ & $5.7-19.7$ \\
\hline $\begin{array}{l}\text { CD8+CD62L+CD45 } \\
\text { RA- }(\%)\end{array}$ & n.d. & 6.9 & 6.1 & n.d. & 9.1 & $11.5(\mathrm{H})$ & 5.2 & $14(\mathrm{H})$ & 7.7 & 1.9 & 6.1 & 3.1 & 2.3 & $1.5-10.3$ \\
\hline $\begin{array}{l}\text { CD8+CD62L- } \\
\text { CD45RA- }(\%)\end{array}$ & n.d. & 4.7 & 7.2 & n.d. & 3.2 & 3.1 & 5.4 & 5.2 & 2.6 & 2.3 & 3 & 6 & 3.8 & $1.1-9.2$ \\
\hline $\begin{array}{l}\text { CD8+CD62L- } \\
\text { CD45RA+ (\%) }\end{array}$ & n.d. & $28.8(\mathrm{H})$ & $8.7(\mathrm{H})$ & n.d. & $19.2(\mathrm{H})$ & $8.4(\mathrm{H})$ & $\begin{array}{l}19.3 \\
(\mathrm{H})\end{array}$ & 1 & 1.9 & 2.5 & 5.1 & 2.4 & 3 & $0.7-7.8$ \\
\hline CD4/CD8 ratio & $0.79(\mathrm{~L})$ & $0.26(\mathrm{~L})$ & $0.87(\mathrm{~L})$ & 2.42 & $0.59(\mathrm{~L})$ & $0.98(\mathrm{~L})$ & $0.93(\mathrm{~L})$ & $0.9(\mathrm{~L})$ & 1.73 & 2.22 & 1.36 & 2.86 & 1.3 & $1.11-5.17$ \\
\hline $\begin{array}{l}\text { CD4+CD45RA+CD3 } \\
1+(\%)\end{array}$ & n.d. & n.d. & 8.6 & n.d. & 2.1 & n.d. & 4.8 & n.d. & n.d. & 13.9 & 4.6 & 9.5 & 18.6 & $1.6-20.2$ \\
\hline $\begin{array}{l}\text { CD4+CD45RA- } \\
\text { CXCR5+(\%) }\end{array}$ & n.d. & n.d. & 3.4 & n.d. & 5 & n.d. & 7.3 & n.d. & n.d. & 7.6 & 8.5 & 3.2 & 2.9 & $1.8-8.9$ \\
\hline $\begin{array}{l}\text { CD4+CD25+FOXP3 } \\
+(\%)\end{array}$ & n.d. & n.d. & 2 & n.d. & 2 & n.d. & $0.6(\mathrm{~L})$ & n.d. & n.d. & 1.6 & $0.9(\mathrm{~L})$ & 2.3 & 1.7 & $1.6-4.3$ \\
\hline
\end{tabular}




\begin{tabular}{|c|c|c|c|c|c|c|c|c|c|c|c|c|c|c|}
\hline CD20 B (ALC) & 76 & $38(\mathrm{~L})$ & $35(\mathrm{~L})$ & 247 & $27(\mathrm{~L})$ & 121 & 92 & 118 & $41(\mathrm{~L})$ & $44(\mathrm{~L})$ & 217 & 154 & $351(\mathrm{H})$ & $59-329$ \\
\hline CD20 B (\%) & 7.6 & $2.4(\mathrm{~L})$ & 3.1 & 17.7 & $1.8(\mathrm{~L})$ & 4.4 & 6.7 & 5.2 & 3.5 & $2.9(\mathrm{~L})$ & 10.8 & 5.7 & 7.4 & $3-19$ \\
\hline $\begin{array}{l}\text { CD20+CD27-IgM+ } \\
(\%)\end{array}$ & n.d. & 78.8 & 84.5 & n.d. & $39.2(\mathrm{~L})$ & 84.2 & 91.2 & 84.8 & $98.7(\mathrm{H})$ & $98.8(\mathrm{H})$ & 89.3 & $53.3(\mathrm{~L})$ & 86.6 & $\begin{array}{l}56.2-91.5(\% \\
\text { of B cells) }\end{array}$ \\
\hline $\begin{array}{l}\text { CD20+CD27+IgM+ } \\
(\%)\end{array}$ & n.d. & 12.0 & 12.5 & n.d. & $45.19(\mathrm{H})$ & $4.3(\mathrm{~L})$ & $3.9(\mathrm{~L})$ & 5.7 & $0.5(\mathrm{~L})$ & $0.9(\mathrm{~L})$ & 6.9 & 29.9 & 7.9 & $\begin{array}{l}4.8-38.5(\%) \\
\text { of B cells) }\end{array}$ \\
\hline $\begin{array}{l}\text { CD20+CD27+IgM- } \\
(\%)\end{array}$ & n.d. & 6.6 & $2(\mathrm{~L})$ & n.d. & 6.5 & 6.1 & $3.2(\mathrm{~L})$ & 6.2 & $0(\mathrm{~L})$ & $0.2(\mathrm{~L})$ & $2.7(\mathrm{~L})$ & 15.4 & $2.6(\mathrm{~L})$ & $\begin{array}{l}4.3-19.9(\% \\
\text { of B cells })\end{array}$ \\
\hline $\begin{array}{l}\text { CD19+CD24++CD3 } \\
8++(\%)\end{array}$ & n.d. & 6.1 & 18.7 & n.d. & $0(\mathrm{~L})$ & 16.8 & 7.7 & 4.9 & 11.1 & $3.2(\mathrm{~L})$ & 10.6 & $4.2(\mathrm{~L})$ & $4.1(\mathrm{~L})$ & $\begin{array}{l}4.7-18.7 \text { (\%) } \\
\text { of B cells) }\end{array}$ \\
\hline $\begin{array}{l}\text { CD19+CD24- } \\
\text { CD38++ (\%) }\end{array}$ & n.d. & 0.6 & 0.3 & n.d. & $0(\mathrm{~L})$ & $0.1(\mathrm{~L})$ & $0.1(\mathrm{~L})$ & 0.4 & $0(\mathrm{~L})$ & $0(\mathrm{~L})$ & $0.1(\mathrm{~L})$ & 1.5 & 0.7 & $\begin{array}{l}0.3-3.6 \text { (\% o o } \\
\text { B cells) }\end{array}$ \\
\hline NK (ALC) & $106(\mathrm{~L})$ & 158 & 130 & 353 & 134 & $104(\mathrm{~L})$ & $85(\mathrm{~L})$ & 336 & $125(\mathrm{~L})$ & $95(\mathrm{~L})$ & 233 & 454 & 209 & 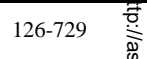 \\
\hline NK (\%) & 10.61 & 10 & 11.5 & 25.2 & 8.9 & $3.8(\mathrm{~L})$ & 6.2 & 14.8 & 10.7 & 6.2 & 11.6 & 16.8 & $4.4(\mathrm{~L})$ & $\begin{array}{ll}6.2-34.6 \stackrel{\bar{\sigma}}{\overline{\bar{\sigma}}} \\
& \\
& \end{array}$ \\
\hline \multicolumn{15}{|c|}{ Immunoglobulins (mg/dL) } \\
\hline $\mathrm{IgG}$ & n.d. & $516(\mathrm{~L})$ & $1001^{*}$ & $672.7(\mathrm{~L})$ & $349(\mathrm{~L})$ & 1147 & n.d. & n.d. & $59.8(\mathrm{~L})$ & $984 *$ & n.d. & n.d. & 740 & $700-1600 \stackrel{\bar{\circ}}{\varrho}$ \\
\hline $\operatorname{IgA}$ & n.d. & $36(\mathrm{~L})$ & $49(\mathrm{~L})$ & 90.5 & $28(\mathrm{~L})$ & 98 & n.d. & n.d. & $<10(\mathrm{~L})$ & $12(\mathrm{~L})$ & n.d. & n.d. & 112 & $70-400 \quad \frac{\frac{0}{\phi}}{i}$ \\
\hline $\operatorname{IgM}$ & n.d. & 15 (L) & $14(\mathrm{~L})$ & 54.3 & $<7(\mathrm{~L})$ & $<10(\mathrm{~L})$ & n.d. & n.d. & $<10(\mathrm{~L})$ & $6(\mathrm{~L})$ & n.d. & n.d. & 98 & $40-230 \quad \stackrel{\bar{\partial}}{\stackrel{\overrightarrow{0}}{0}}$ \\
\hline \multicolumn{15}{|c|}{ Auto antibodies } \\
\hline & n.d. & n.d. & $\begin{array}{l}\text { Anti-platelet } \\
\text { Ab positive, } \\
\text { Coombs } \\
\text { negative. }\end{array}$ & n.d. & n.d. & n.d. & n.d. & n.d. & n.d. & $\begin{array}{l}\text { Coombs } \\
\text { positive } \\
\text { ANA positive }\end{array}$ & n.d. & n.d. & $\begin{array}{l}\text { ANA positive, } \\
\text { Anti-dsDNA } \\
\text { negative, } \\
\text { Coombs negative. }\end{array}$ & 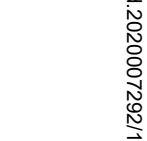 \\
\hline \multicolumn{15}{|c|}{ Vaccine response } \\
\hline & n.d. & n.d. & $\begin{array}{l}\text { Progressive } \\
\text { loss of } \\
\text { protective } \\
\text { titers towards } \\
\text { pneumococcal } \\
\text { and } \\
\text { HiB antigens }\end{array}$ & n.d. & $\begin{array}{l}1 / 14 \\
\text { pneumococcal, } \\
\text { non protective } \\
\text { titers to tetanus } \\
\text { toxoid, } \\
\text { diphtheria } \\
\text { toxoid, measles, } \\
\text { mumps, rubella } \\
\text { or varicella }\end{array}$ & $\begin{array}{l}5 / 23 \text { to } \\
\text { pneumococcal } \\
\text { vaccine } \\
\text { response (Pre), } \\
8 / 23 \text { to } \\
\text { pneumococcal } \\
\text { vaccine } \\
\text { response } \\
\text { (Post), } \\
\text { Tetanus } \\
\text { protective }\end{array}$ & n.d. & n.d. & n.d. & $\begin{array}{l}2 / 14 \\
\text { pneumococcal, } \\
\text { protected to } \\
\text { diphtheria } \\
\text { and tetanus }\end{array}$ & n.d. & n.d. & n.d. & 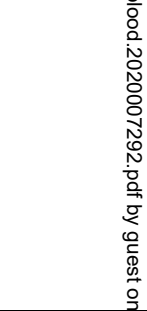 \\
\hline \multicolumn{15}{|c|}{ Clinical history } \\
\hline & $\begin{array}{l}\text { Asympto- } \\
\text { matic }\end{array}$ & $\begin{array}{l}1 \\
\text { pneumonia } \\
\text { (age 25y), } \\
\text { pernicious } \\
\text { anemia }\end{array}$ & $\begin{array}{l}\text { ITP, } \\
\text { progressive } \\
\text { hypogamma- } \\
\text { globulinemia }\end{array}$ & $\begin{array}{l}\text { Type } 2 \\
\text { diabetes, } \\
\text { hypo- } \\
\text { thyroidism }\end{array}$ & $\begin{array}{l}\text { T-ALL, } \\
\text { Recurrent } \\
\text { diarrhea, } \\
\text { Hypogamma- } \\
\text { globulinemia }\end{array}$ & $\begin{array}{l}\text { Pneumonia } \\
\text { (x 2, starting } \\
\text { in her 50’s) }\end{array}$ & $\begin{array}{l}\text { Asympto- } \\
\text { matic }\end{array}$ & $\begin{array}{l}\text { Asympto- } \\
\text { matic }\end{array}$ & $\begin{array}{l}\text { Recurrent } \\
\text { URIs, } \\
\text { Hypogamma- } \\
\text { globulinemia, } \\
\text { fibromyalgia }\end{array}$ & $\begin{array}{l}\text { ITP, } \\
\text { AIHA, } \\
\text { Hypogamma- } \\
\text { globulinemia } \\
\text { s/p Rituximab }\end{array}$ & Hashimoto's & $\begin{array}{l}\text { Asympto- } \\
\text { matic }\end{array}$ & $\begin{array}{l}\text { Burkitt lymphoma, } \\
\text { Lymphadeno-pathy, } \\
\text { ITP, } \\
\text { Neutropenia }\end{array}$ & $\begin{array}{l}\text { Non } \\
\text { N } \\
\text { N }\end{array}$ \\
\hline
\end{tabular}


Table 1. Clinical and laboratory feature in patients with heterozygous $I K Z F 1$ mutations

$\mathrm{H}$ and $\mathrm{L}$ indicate values above/below the normal range (respectively) compared to adult controls in NIH Clinical Center. The B cells subsets are expressed as the percentage of $\mathrm{CD} 19^{+}$cells.

*The patient was receiving IgG replacement therapy.

n.d indicates not determined.

ITP: Idiopathic thrombocytopenic purpura

AIHA: Autoimmune hemolytic anemia 


\begin{tabular}{|c|c|c|c|c|c|c|c|c|c|}
\hline \multicolumn{2}{|c|}{ Functional test } & WT & $\begin{array}{l}\mathrm{R} 213 * \\
\text { (DD) }\end{array}$ & $\begin{array}{l}\text { S427* } \\
\text { (DD) }\end{array}$ & $\begin{array}{l}\text { C467R } \\
\text { (DD) }\end{array}$ & $\begin{array}{l}\text { R502L } \\
\text { (DD) }\end{array}$ & $\begin{array}{c}\text { Y462* } \\
(\text { Del } \\
\text { ZF5+6) }\end{array}$ & $\begin{array}{l}\text { R162Q } \\
(\mathrm{HI})\end{array}$ & $\begin{array}{l}\text { N159S } \\
(\mathrm{DN})\end{array}$ \\
\hline \multicolumn{2}{|c|}{ Dimerization } & +++ & - & - & - & + & - & +++ & +++ \\
\hline \multicolumn{2}{|c|}{$\begin{array}{c}\text { PC-HC } \\
\text { (WT or Mutant alone) }\end{array}$} & +++ & - & - & - & +++ & - & - & - \\
\hline $\begin{array}{c}\text { PC-HC } \\
(\text { co- } \\
\text { expression } \\
\text { with WT) }\end{array}$ & $\begin{array}{l}\text { Mut-Mut } \\
\text { WT-Mut } \\
\text { WT-WT }\end{array}$ & $\begin{array}{l}\text { NA } \\
\text { NA } \\
+++\end{array}$ & $\begin{array}{c}- \\
- \\
++\end{array}$ & $\begin{array}{c}- \\
- \\
++\end{array}$ & $\begin{array}{c}- \\
- \\
++\end{array}$ & $\begin{array}{l}+++ \\
+++ \\
+++\end{array}$ & $\begin{array}{c}- \\
- \\
++\end{array}$ & $\begin{array}{c}- \\
++ \\
++\end{array}$ & $\begin{array}{l}- \\
- \\
-\end{array}$ \\
\hline $\begin{array}{c}\text { DNA } \\
\text { binding }\end{array}$ & $\begin{array}{l}\text { Monomer } \\
\text { Multimer }\end{array}$ & $\begin{array}{l}+/++ \\
+++\end{array}$ & $\begin{array}{c}+++ \\
-\end{array}$ & $\begin{array}{c}+++ \\
-\end{array}$ & $\begin{array}{l}+ \\
+\end{array}$ & $\begin{array}{c}++ \\
+\end{array}$ & $\begin{array}{c}+++ \\
-\end{array}$ & - & - \\
\hline \multicolumn{2}{|c|}{ Sumoylation } & +++ & + & + & + & +++ & + & +++ & +++ \\
\hline \multicolumn{2}{|c|}{ HDAC1 binding } & + & $+/-$ & $+/-$ & +++ & ++ & $+/-$ & + & + \\
\hline \multicolumn{2}{|c|}{$\begin{array}{l}\text { Protein stability } \\
\text { (CHX treated) }\end{array}$} & +++ & + & + & + & ++ & + & +++ & +++ \\
\hline \multicolumn{2}{|c|}{ T/B/Myeloid abnormalities } & NA & \multicolumn{4}{|c|}{$\mathrm{T}-/ \mathrm{B}++/ \mathrm{M}-$} & NA & $\begin{array}{c}\mathrm{T}- \\
/ \mathrm{B}+++/ \mathrm{M}-\end{array}$ & $\mathrm{T}+++/ \mathrm{B}+++/ \mathrm{M}+++$ \\
\hline \multicolumn{2}{|c|}{ Infections } & $\mathrm{NA}$ & \multicolumn{4}{|c|}{$-/+$} & NA & +++ & +++ \\
\hline \multicolumn{2}{|c|}{ Autoimmune cytopenias } & NA & \multicolumn{4}{|c|}{$++/+++$} & NA & + & - \\
\hline \multicolumn{2}{|c|}{ Hematologic malignancies } & NA & \multicolumn{4}{|c|}{$++/+++$} & NA & + & $+/++$ \\
\hline
\end{tabular}

Table 2. Summary of various effects of germline heterozygous IKZF1 mutations

All mutations were found in the patients, except Y462* (a laboratory-generated mutant to test the effect of deletion of ZF5 and ZF6, gray color). R162Q and N159S are previously reported DNA binding defective IKZF1 mutations acting by haploinsufficiency (HI) or dominant negative (DN) effect, respectively. " $+/++/+++$ " indicates the strength of each IKAROS function test, being " +++ " the strongest and "." not detected (all compared to WT); NA, indicates not applicable. 
Figure 1

A

$\square$ Mutation positive (Heterozygous)

$\square$ Antibody deficiency

$\mathbb{Z}$ Recurrent infection

$\square$ Autoimmune/immune dysregulation

$\square$ Malignancy

$\begin{array}{cc}\text { Family A } & \text { Family B } \\ \text { c.637C }>\text { T } & \text { c. } 1280 \mathrm{C}>\mathrm{A} \\ \text { p.R213* } & \text { p.S427* }\end{array}$

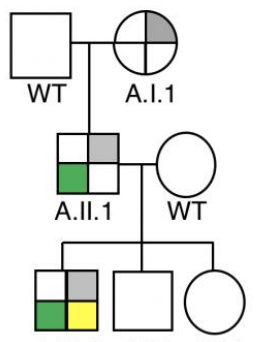

A.III.1 WT WT
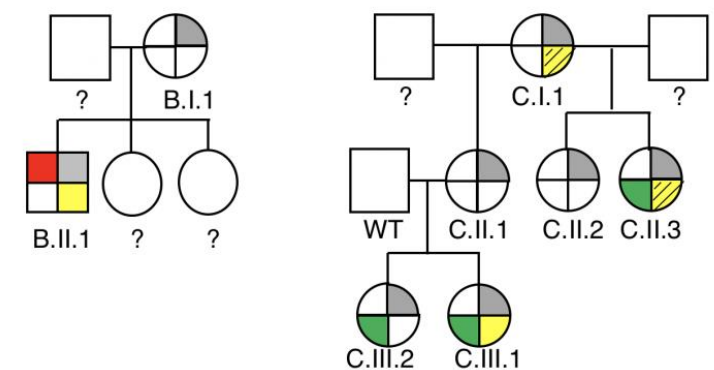

Family D

c. $1505 \mathrm{G}>\mathrm{T}$

p.R502L

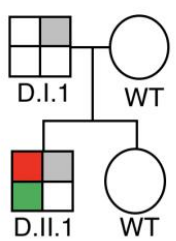

B

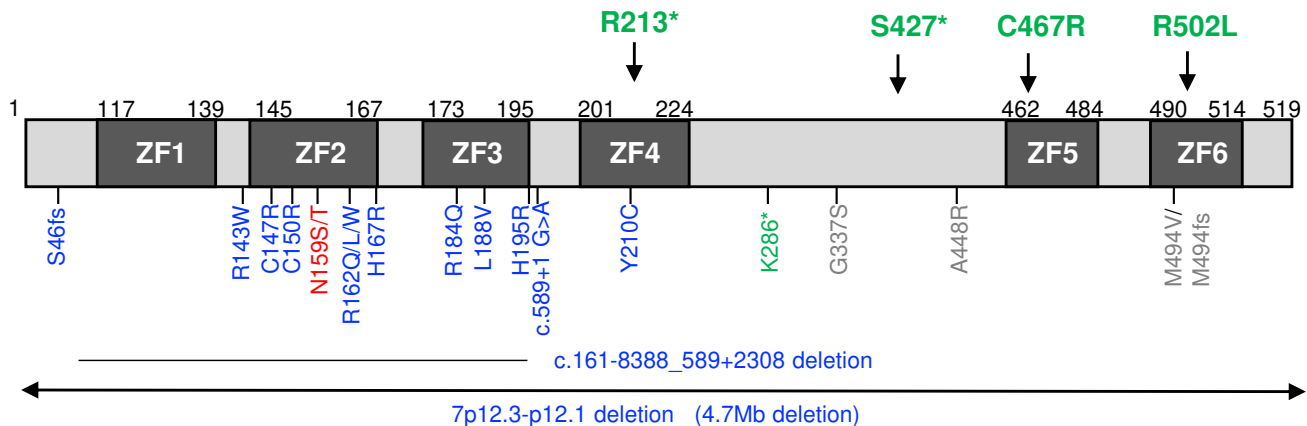

7p12.3-p12.1 deletion (4.7Mb deletion)

C

ZF5

ZF6

Homo.sapiens RVVSTSGEQMKVYKCEHCRVLFLDHVMYTIHMGCHGFRDPFECNMCGYHSQDRYEFSSHITRGEHRFHMS P.Troglodytes RVVSTSGEQMKVYKCEHCRVLFLDHVMYTIHMGCHGFRDPFECNMCGYHSQDRYEFSSHITRGEHRFHMS M.Mulatta RVVSTSGEQMKVYKCEHCRVLFLDHVMYTIHMGCHGFRDPFECNMCGYHSQDRYEFSSHITRGEHRFHMS C. Lupus RVIGTSGEPMKVYKCEHCRVLFLDHVMYTI HMGCHGFRDPFECNMCGYHSQDRYEFSSHITRGEHRFHMS B.Taurus RVIGTSGEALKVYRCEHCRVLFLDHVMYTIHMGCHGFRDPFECNMCGYHSQDRYEFSSHITRGEHRFHMS M.Musculus RVVSTSGEQLKVYKCEHCRVLFLDHVMYTIHMGCHGFRDPFECNMCGYHSODRYEFSSHITRGEHRYHLS G.Gallus KVISSNGEQVRVYKCEHCRVLFLDHVMYTI HMGCHGFRDPFECNMCGYHSQDRYEFSSHITRGEHRFHMS D.Rerio KVLSGDGEELRAYRCIHCRVLFLDHVMYTI HMGCHGFRDPFECNLCGYRSODRYEFSSHITRGEHRI--X.Tropicalis KVVSGSGESLKVHKCEHCRVIFLDHVMYTIHMGCHGFRDPFECNMCGYQSQDRYEFSSHITRGEHRFNMG C467R

R502L 
Figure 2
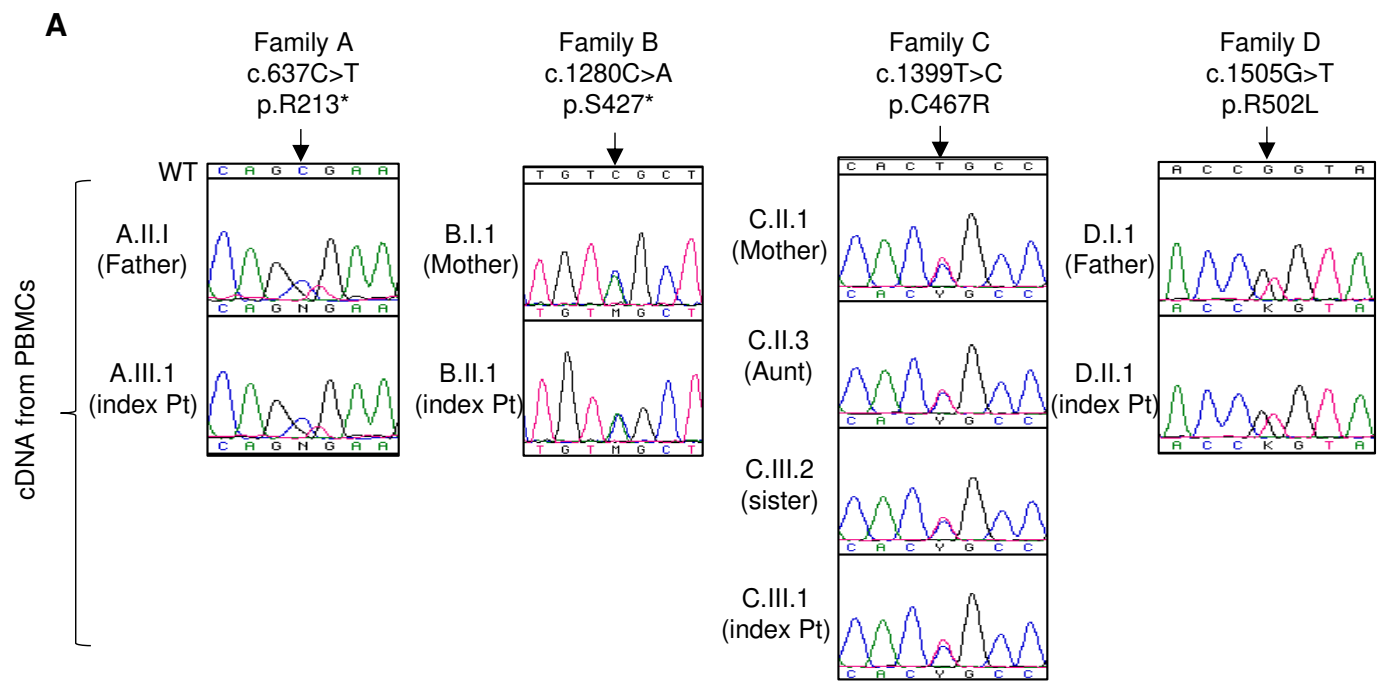

B

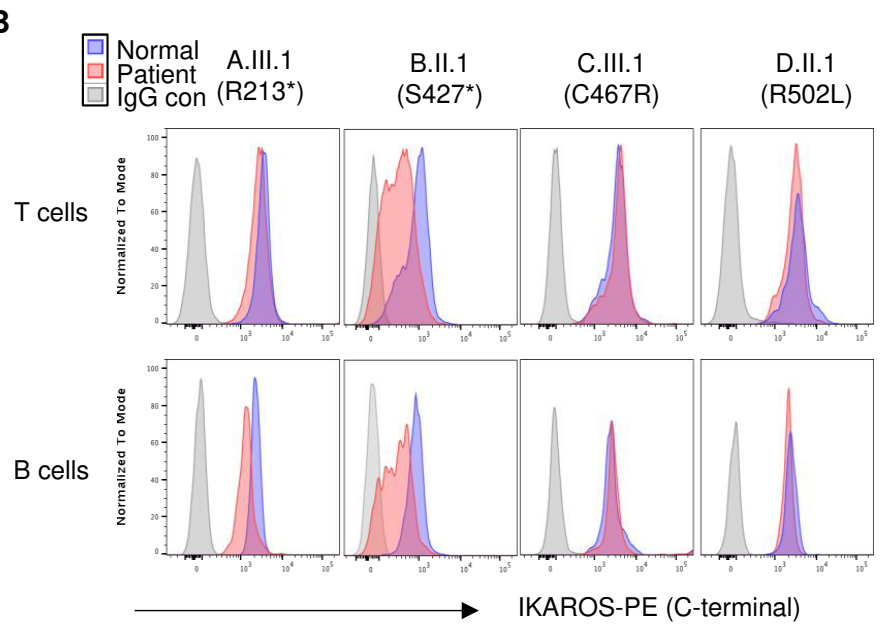

C

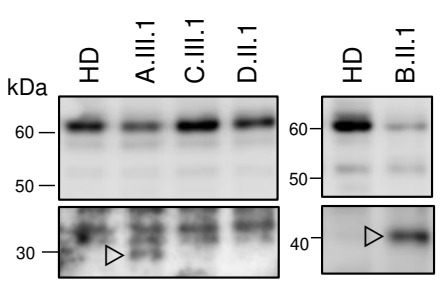

WB: IKAROS (N-terminal) 
Figure 2

D

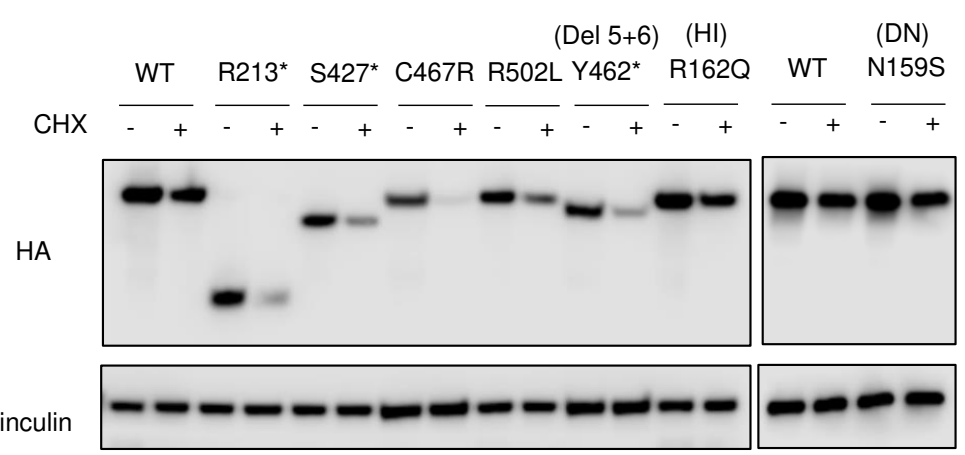

E

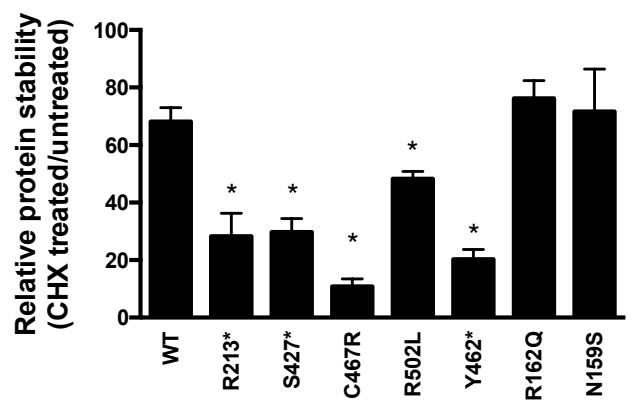


Figure 3

A
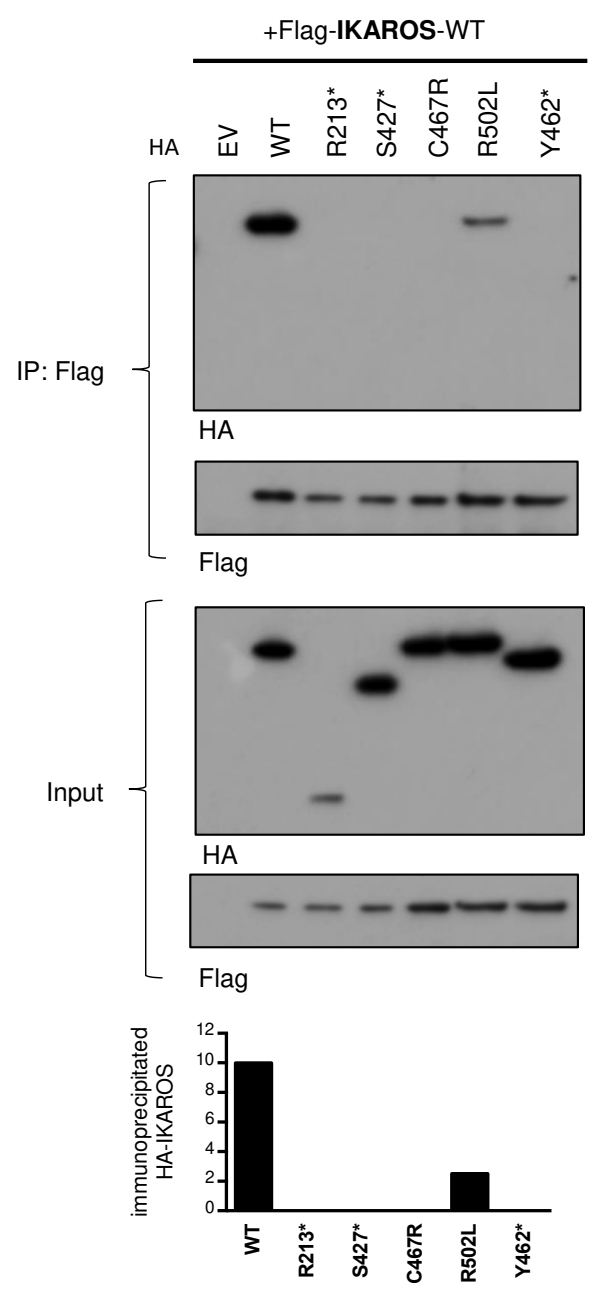

B
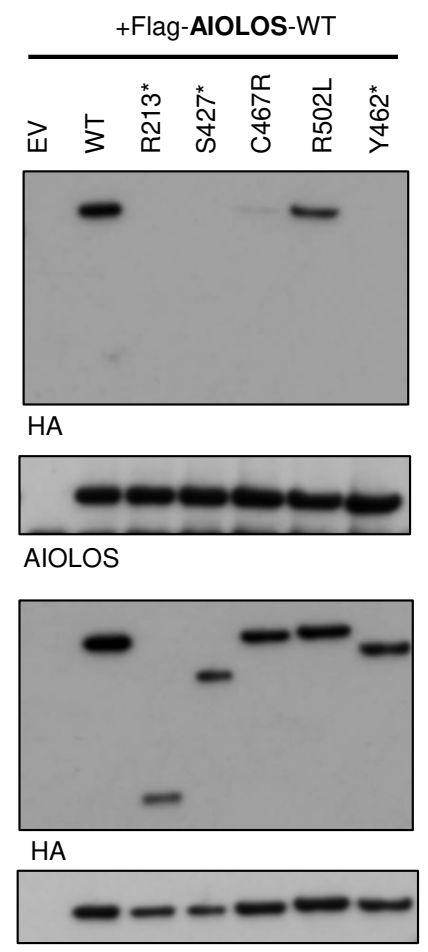

AIOLOS

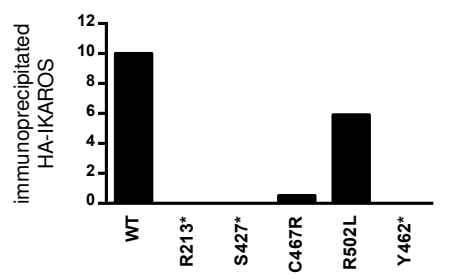

C

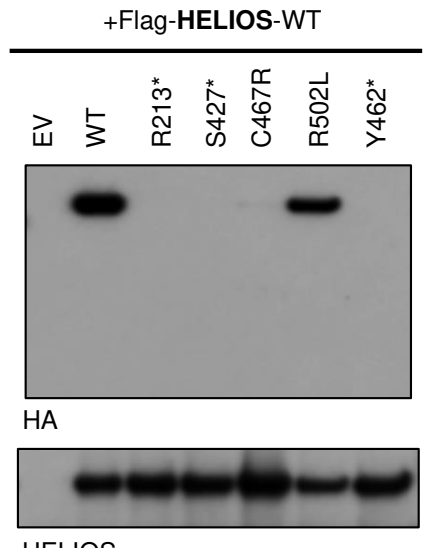

HELIOS

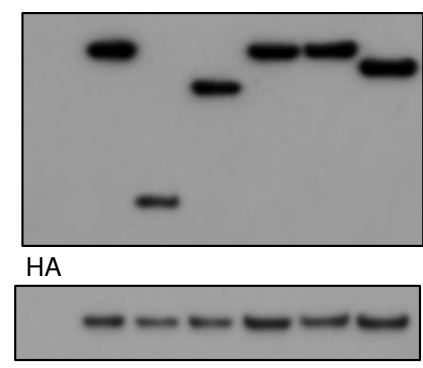

HELIOS

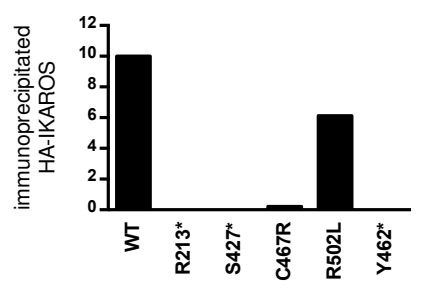


Figure 4

A
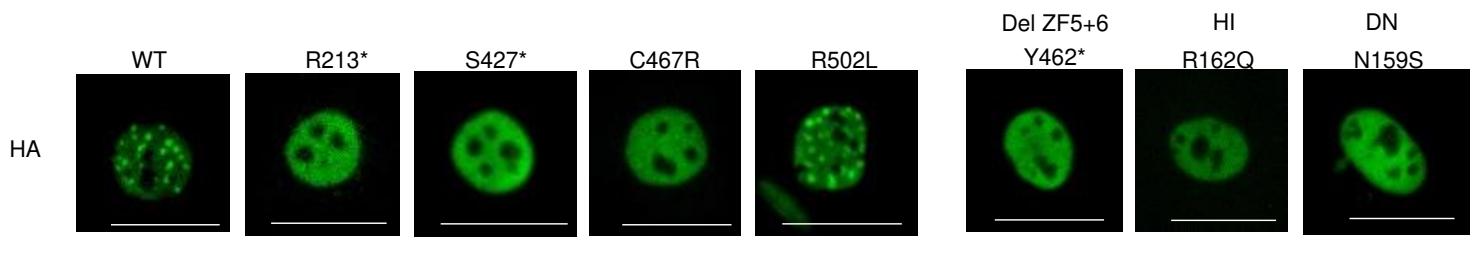

B

+ Flag-IKAROS WT

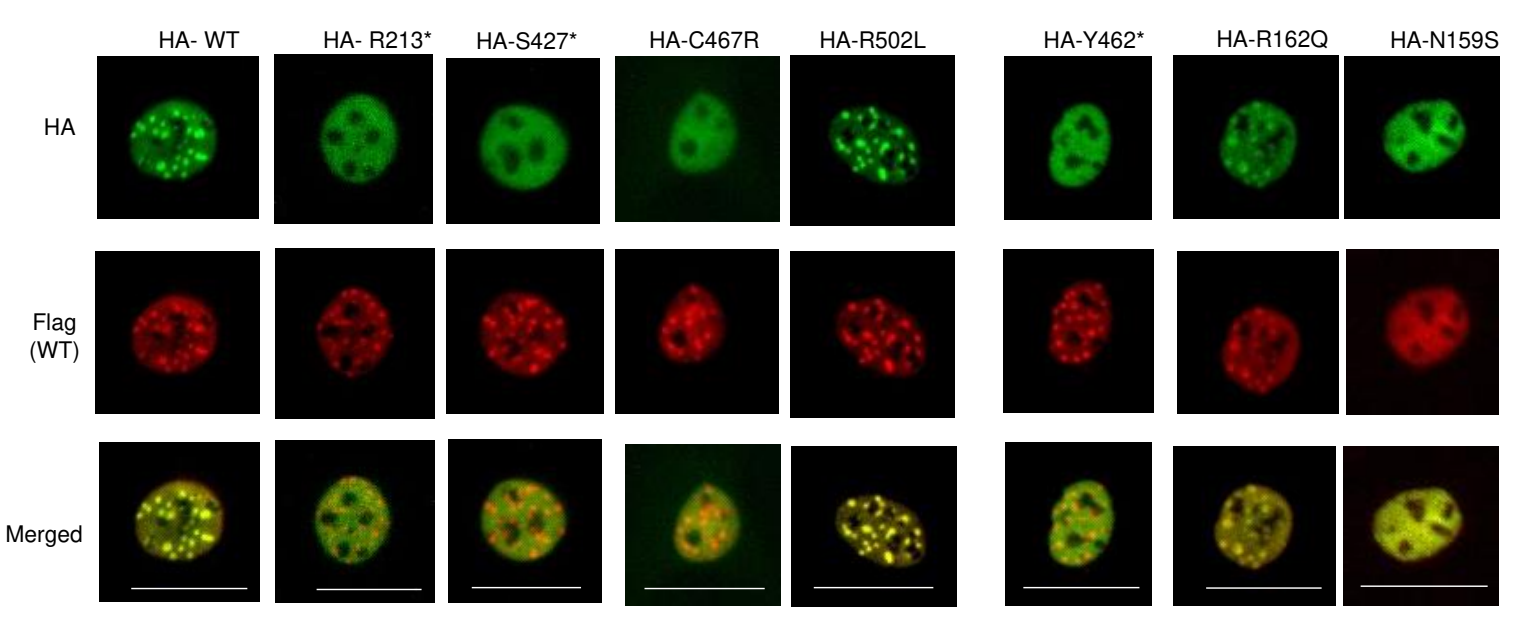


Figure 5

A

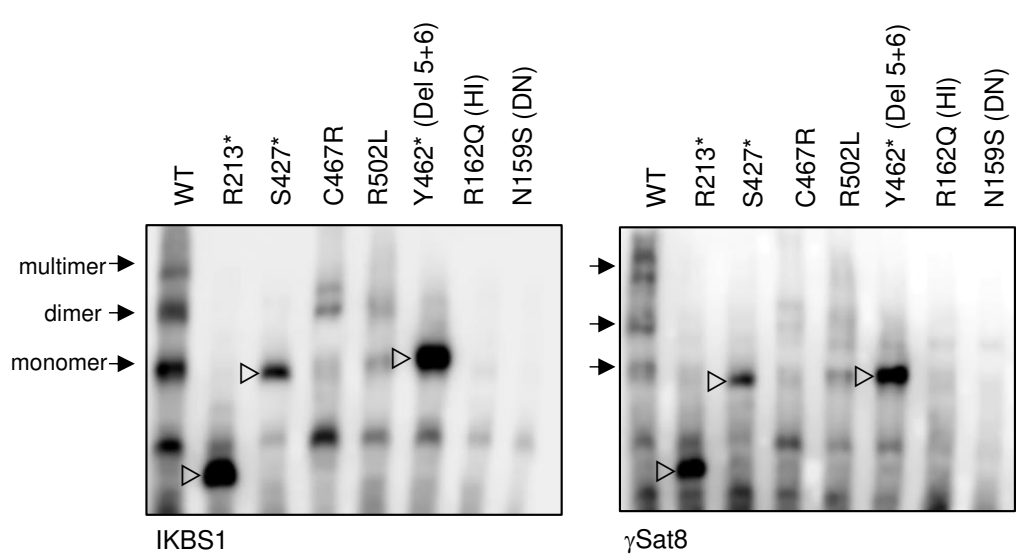

B
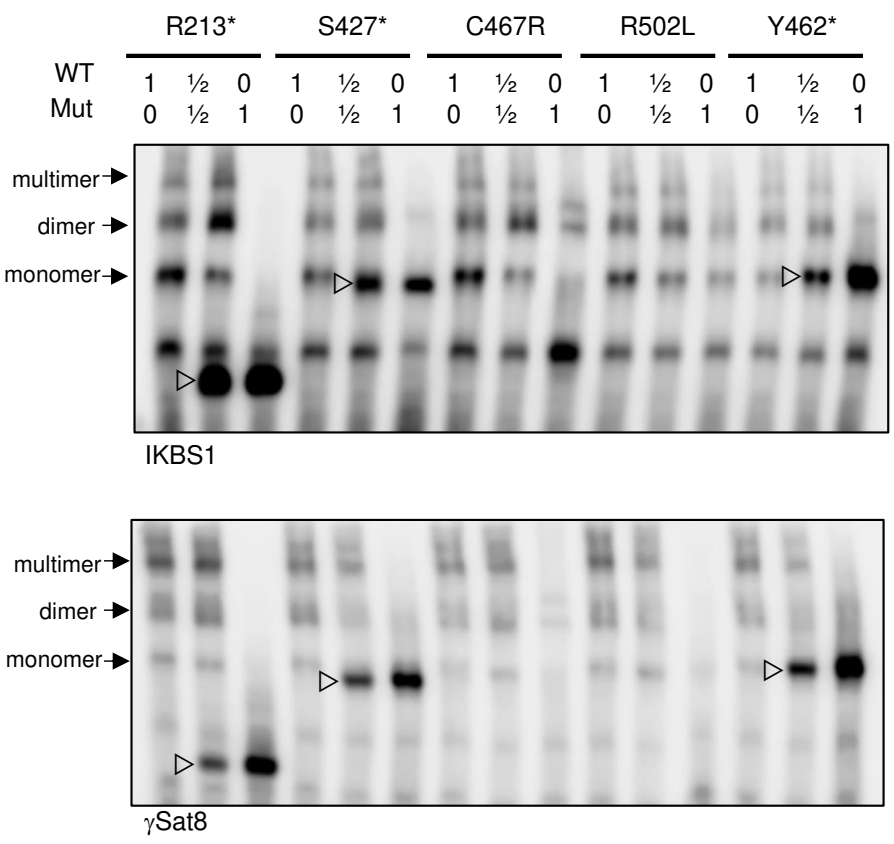

C.

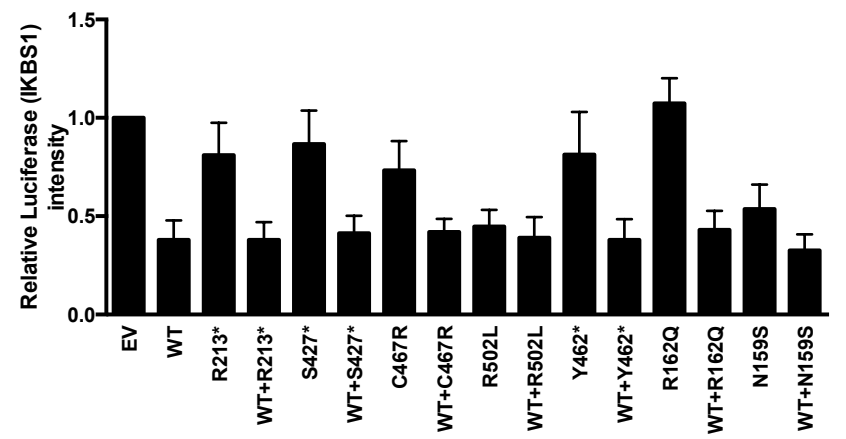


Figure 6

A

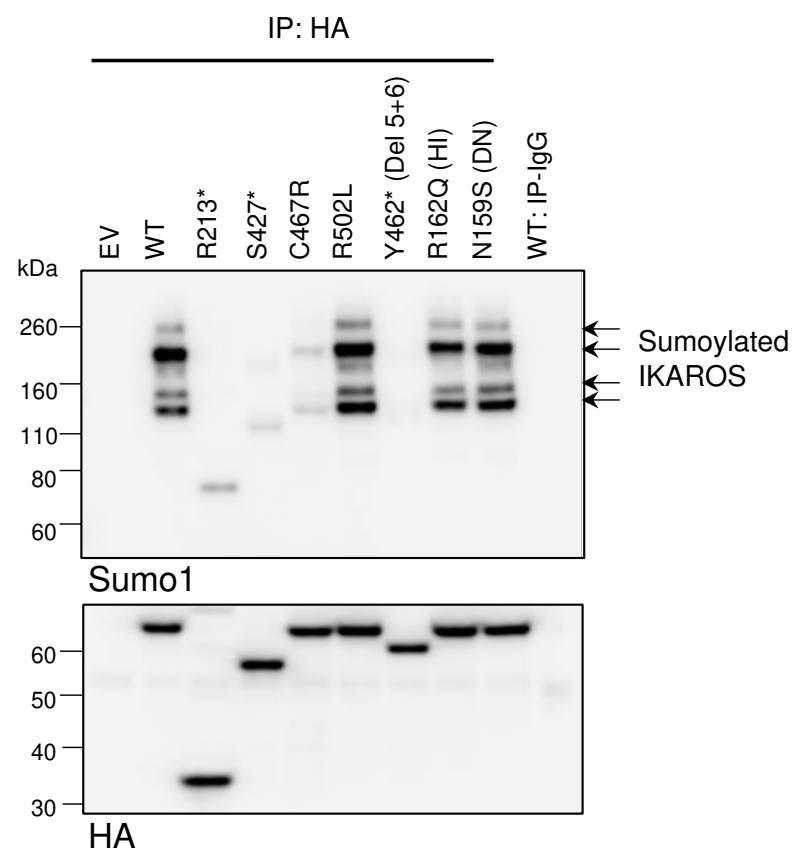

B
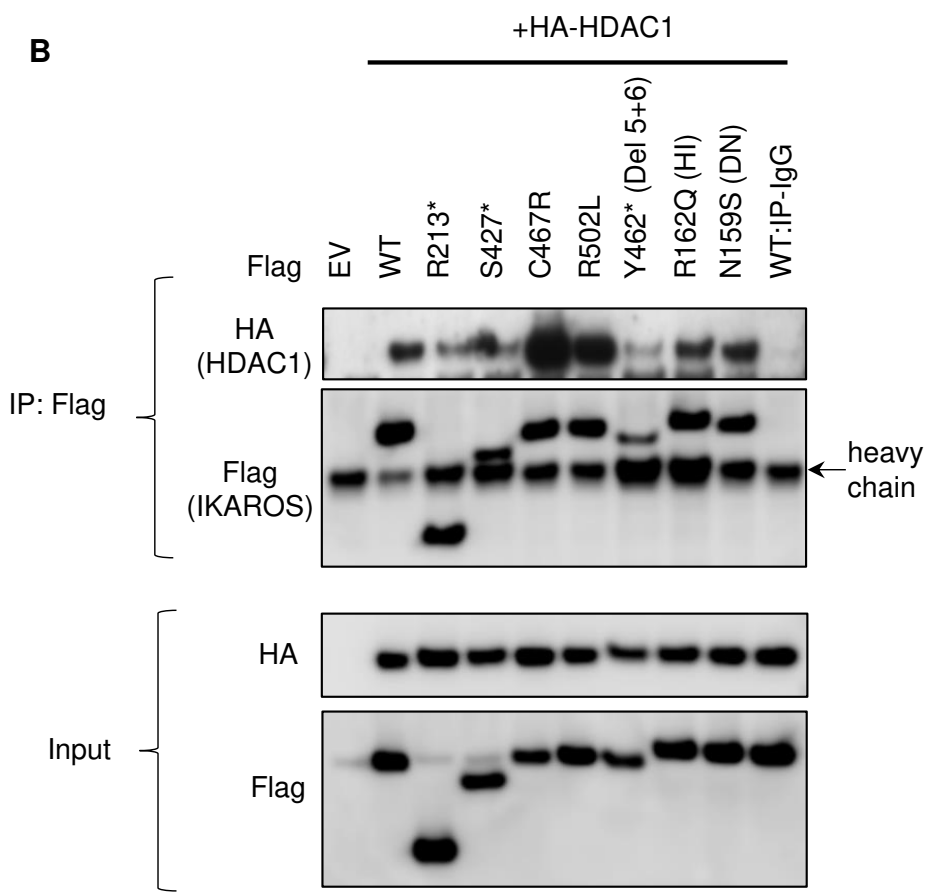
Figure 7

A

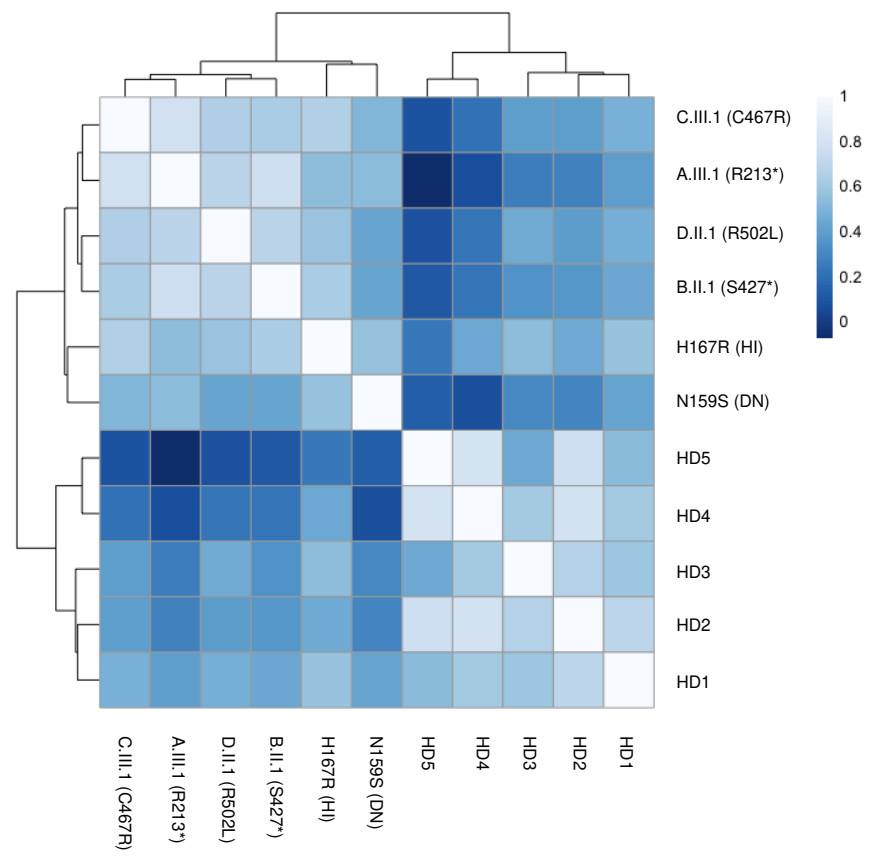

B

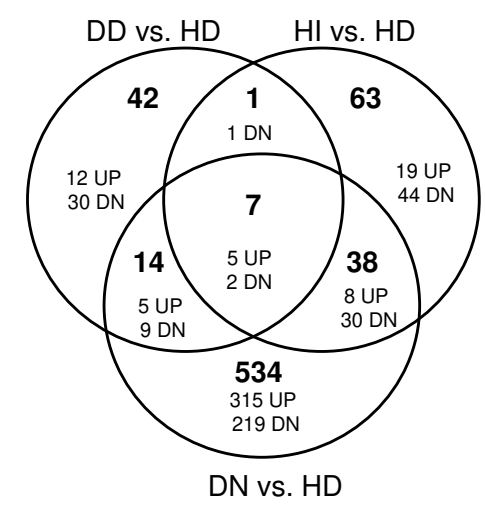

DN vs. HD 